\title{
iFit: a simple method for measuring volcanic SO2 without a measured Fraunhofer reference spectrum
}

DOI:

10.1016/j.jvolgeores.2020.107000

\section{Document Version}

Accepted author manuscript

Link to publication record in Manchester Research Explorer

\section{Citation for published version (APA):}

Esse, B., Burton, M., Varnam, M., Kazahaya, R., \& Salerno, G. (2020). iFit: a simple method for measuring volcanic SO2 without a measured Fraunhofer reference spectrum. Journal of Volcanology and Geothermal Research, 402, [107000]. https://doi.org/10.1016/j.jvolgeores.2020.107000

\section{Published in:}

Journal of Volcanology and Geothermal Research

\section{Citing this paper}

Please note that where the full-text provided on Manchester Research Explorer is the Author Accepted Manuscript or Proof version this may differ from the final Published version. If citing, it is advised that you check and use the publisher's definitive version.

\section{General rights}

Copyright and moral rights for the publications made accessible in the Research Explorer are retained by the authors and/or other copyright owners and it is a condition of accessing publications that users recognise and abide by the legal requirements associated with these rights.

\section{Takedown policy}

If you believe that this document breaches copyright please refer to the University of Manchester's Takedown Procedures [http://man.ac.uk/04Y6Bo] or contact uml.scholarlycommunications@manchester.ac.uk providing relevant details, so we can investigate your claim.

\section{OPEN ACCESS}




\title{
iFit: a simple method for measuring volcanic $\mathrm{SO}_{2}$ without a measured Fraunhofer reference spectrum
}

\author{
Ben Esse ${ }^{\mathrm{a}, *}$, Mike Burton $^{\mathrm{a}}$, Matthew Varnam ${ }^{\mathrm{a}}$, Ryunosuke Kazahaya $^{\mathrm{b}, \mathrm{c}}$, \\ Giuseppe Salerno ${ }^{\mathrm{d}}$ \\ ${ }^{a}$ Department of Earth and Environmental Sciences, The University of Manchester, \\ Manchester, M13 9PL, UK \\ ${ }^{b}$ Japan Meteorological Agency, Tokyo, Japan \\ ${ }^{c}$ Research Institute of Earthquake and Volcano Geology, Geological Survey of Japan, \\ National Institute of Advanced Industrial Science and Technology, Higashi 1-1-1, Tsukuba \\ 305-8576, Japan \\ ${ }^{d}$ Istituto Nazionale di Geofisica e Vulcanologia, Osservatorio Etneo, sezione di Catania, \\ Piazza Roma 2, 95123, Catania, Italy
}

\begin{abstract}
Accurate quantification of the emission rate of sulphur dioxide $\left(\mathrm{SO}_{2}\right)$ from volcanoes provides both insights into magmatic processes and a powerful monitoring tool for hazard mitigation. The primary method for measuring magmatic $\mathrm{SO}_{2}$ is Differential Optical Absorption Spectroscopy (DOAS) of UV scattered sunlight spectra, in which a reference spectrum taken outside the plume is used to quantify the $\mathrm{SO}_{2}$ slant column density inside the plume. This can lead to problems if the reference spectrum is contaminated with $\mathrm{SO}_{2}$ as this will result in a systematic underestimation of the retrieved $\mathrm{SO}_{2}$ slant column density, and therefore emission rate. We present a new analysis method, named "iFit", which retrieves the $\mathrm{SO}_{2}$ slant column density from UV spectra by directly fitting the measured intensity spectrum at high spectral resolution $(0.01 \mathrm{~nm})$ using a literature solar reference spectrum and measured instrument characteristics. This eliminates the requirement for a measured reference spectrum, providing a "point and shoot" method for quantifying $\mathrm{SO}_{2}$ slant column densities. We show that iFit retrieves correct $\mathrm{SO}_{2}$ slant column densities in a series of test cases, finding agreement with existing methods. We propose that iFit is suitable for both traverse measurements and permanent scanning stations, and could be integrated into volcano monitoring networks at observatories. Finally, we provide an open source software implementation of iFit with a user friendly graphical interface to allow users to easily utilise iFit.
\end{abstract}

Keywords: Sulphur Dioxide, Volcano monitoring, UV Spectroscopy, Remote sensing

\footnotetext{
${ }^{*}$ Corresponding author

Email address: benjamin.esse@manchester.ac.uk (Ben Esse)
} 


\section{Introduction}

Measuring volcanic sulphur dioxide $\left(\mathrm{SO}_{2}\right)$ emission rates is a valuable tool in volcanology for investigating magmatic processes (Fischer et al., 1994; DelgadoGranados et al., 2001; Oppenheimer et al., 2011; Salerno et al., 2018), monitoring

5 volcanic activity (Sparks, 2003; Bonaccorso et al., 2004) and quantifying global emissions of other volcanic gases (Burton et al., 2013). $\mathrm{SO}_{2}$ is used instead of other more abundant gases (such as $\mathrm{CO}_{2}$ or $\mathrm{H}_{2} \mathrm{O}$ ) as it has a very low atmospheric concentration $(0.1-70 \mathrm{ppb}$ with respect to a typical dilute plume concentration of 1 - 2 ppm (Symonds et al., 1994)) and has a strong UV absorp-

10 tion which can be measured with scattered sunlight. This makes $\mathrm{SO}_{2}$ relatively easy to detect and quantify, a fact that was exploited through the widespread use of correlation spectroscopy (COSPEC) to determine volcanic $\mathrm{SO}_{2}$ emission rates (Moffat \& Millan, 1971; Caltabiano et al., 1994; Williams-Jones et al., 2008).

15 The development of miniature UV spectrometers further revolutionised $\mathrm{SO}_{2}$ emission rate quantification (Galle et al., 2002; McGonigle, 2007; Kantzas \& McGonigle, 2008; Kantzas et al., 2009), and networks of scanning spectrometers have now become the go-to tool worldwide for monitoring volcanic gas emission (Edmonds et al., 2003; Burton et al., 2009; Salerno et al., 2009a,b; Galle et al., 20 2010). These spectrometers typically measure scattered UV sunlight that passes through the volcanic plume, from which the $\mathrm{SO}_{2}$ slant column density (SCD) is retrieved using Differential Optical Absorption Spectroscopy (DOAS) (e.g., Platt \& Stutz, 2008).

The widespread use of DOAS has been further cemented by its ability to

25 detect and quantify other volcanic gases, such as $\mathrm{BrO}$ (Bobrowski et al., 2003; Bobrowski \& Platt, 2007; Lübcke et al., 2014), $\mathrm{H}_{2} \mathrm{~S}$ (O'Dwyer et al., 2003), OClO (General et al., 2015; Kern \& Lyons, 2018) and $\mathrm{H}_{2} \mathrm{O}$ (Kern et al., 2017). There are various software packages available that allow DOAS analysis to be performed, such as DOASIS (Kraus, 2006), QDOAS (Danckaert et al., 2017) and

30 UVolc (Kantzas et al., 2012). The introduction of $\mathrm{SO}_{2}$ cameras, which allow $\mathrm{SO}_{2}$ column images to be collected (Mori \& Burton, 2006; Bluth et al., 2007), has further diversified the use of UV spectrometers as they are often used to provide the necessary $\mathrm{SO}_{2}$ calibration (Lübcke et al., 2013; Burton et al., 2015a; Kern et al., 2015a). Satellites may also be used to measure $\mathrm{SO}_{2}$ emission rate 35 time series when combined with meteorological data (Carn et al., 2017; Pardini et al., 2017; Theys et al., 2017; Pardini et al., 2018; Queißer et al., 2019), and the validation of such measurements is often achieved through comparison with ground-based measurements.

The traditional DOAS approach utilises a measured Fraunhofer reference

40 spectrum (FRS) to determine the SCDs of the gases of interest in the plume spectrum. This is achieved by taking the negative natural logarithm of the ratio of the plume and Fraunhofer reference spectra to produce an optical depth spectrum, from which the $\mathrm{SO}_{2} \mathrm{SCD}$ is retrieved. This is advantageous as it automatically removes instrumental features and spectral signatures of atmo-

45 spheric gases, allowing for low detection limits of the species of interest. One 
drawback of this method, however, is that the SCD retrieved is not absolute, but the relative SCD with respect to the FRS. This means that if any gas is present in the FRS this will lead to an underestimation of the true SCD in the volcanic plume. In order to determine absolute SCDs care must be taken to ensure that the FRS is taken well away from the plume, or that a suitable correction is applied to take account of any contamination. This was addressed by Galle et al. (2010), for example, by using the zenith pointing spectrum as the FRS and applying an offset SCD that is determined from the lowest $20 \%$ of the SCDs in that scan to account for any $\mathrm{SO}_{2}$ contamination. This method works

55 if there are regions of clear sky visible to the scanner, but will fail if the plume is present in more than $80 \%$ of the scan. Scanning networks also often use a "completeness" factor to assess how much of a plume is visible to the scanner from its shape (Salerno et al., 2009a; Galle et al., 2010).

The problem of contamination of the FRS led to the development of analysis techniques that do not require a measured FRS, instead using a synthetic spectrum to determine the absolute $\mathrm{SO}_{2}$ SCD (e.g., Salerno et al., 2009b; Lübcke et al., 2016). These methods do, however, require significant characterisation prior to measurements: for example Lübcke et al. (2016), which could be considered the current state of the art, employ a principal components analysis

65 (PCA) approach to describe the residual features from $\sim 5$ days of recorded plume free spectra. These spectra will be collected through the normal operation of a permanent scanning station, but this would be unsuitable for more sporadic measurements such as traverses, or for short term campaign style measurements of volcanic $\mathrm{SO}_{2}$ emission rates.

70 We present a new spectral analysis method, named "iFit", for retrieval of the absolute $\mathrm{SO}_{2} \mathrm{SCD}$ through a direct fit of the measured intensity spectrum without a measured FRS from the measurement spectrometer. This is achieved using a forward model built on a high resolution pre-measured literature Fraunhofer spectrum. A one-off measurement of the specific spectrometer flat field 75 spectrum (the pixel to pixel change in quantum efficiency) is used to correct for instrumental effects, which is easily characterised before measurement.

The method of using a direct fit from a modelled spectrum is not entirely new. Similar methods have been applied, for example, in satellite UV retrievals (e.g. Lerot et al., 2010; Van Roozendael et al., 2012) as well as for IR measo surements (Griffith, 1996; Oppenheimer et al., 1998; Burton et al., 2000). This approach, however, is not widely applied to ground-based UV measurements of volcanic plumes which are a major source of volcanic gas emission rate data. For this reason iFit may be a useful method for the volcanological community to potentially improve the accuracy of volcanic $\mathrm{SO}_{2}$ emission rate data. An open 5 source implementation of iFit is available online which has been designed with a user-friendly graphical interface (https://github.com/benjaminesse/iFit).

This paper is structured as follows. We begin with an overview of the traditional DOAS methodology and describe the corrections routinely applied (Section 2.1) before discussing the iFit procedure (Section 2.2) and emission rate 90 calculation (Section 2.3). The instrument details are then outlined alongside the measurement methodology (Section 3), followed by a series of demonstra- 
tion cases performed to test the accuracy and robustness of iFit (Section 4). We conclude with a discussion of the benefits and drawbacks of the iFit method (Section 5).

\section{Retrieval of volcanic $\mathrm{SO}_{2} \mathrm{SCD}$ from UV spectra}

\section{1. $D O A S$}

Currently, the most widely used technique for volcanic $\mathrm{SO}_{2} \mathrm{SCD}$ retrievals is DOAS. A full description is given by Platt \& Stutz (2008), but a brief overview of the key points on its application to ground-based remote sensing of volcanic plumes will be provided here. For clarity the traditional DOAS approach currently widely used in volcanology will be referred to as "traditional DOAS" from here.

In traditional DOAS the plume spectrum, $I(\lambda)$, is divided by a FRS taken outside the plume, $I_{0}(\lambda)$, to produce a transmittance spectrum. The optical depth, $\tau(\lambda)$, is then found by taking the negative natural logarithm of the transmittance spectrum. The gas SCD is related to the optical depth according to the Beer-Lambert law:

$$
\tau(\lambda)=-\ln \left[\frac{I(\lambda)}{I_{0}(\lambda)}\right]=\sum_{i}\left[\sigma_{i}(\lambda) \cdot a_{i}\right]
$$

where $\sigma_{i}(\lambda)$ is the wavelength dependant absorption cross-section, $a_{i}$ is the gas SCD, and $i$ represents the individual absorbing species. For traditional DOAS the FRS contains absorption from atmospheric gases, allowing these to be automatically cancelled out through the division of the FRS and measurement spectra. The individual gas SCDs of interest can then be retrieved by varying $a_{i}$ to minimise the $\chi^{2}$ value (sum of the squared residual between the measurement and the model).

Equation 1 describes the case of absorbing gases only, but in reality for atmospheric measurements of scattered sunlight the roles of Rayleigh and Mie scattering must also be taken into account:

$$
\tau(\lambda)=\sum_{i}\left[\sigma_{i}(\lambda) \cdot a_{i}\right]+\epsilon_{R}(\lambda)+\epsilon_{M}(\lambda)
$$

where $\epsilon_{R}$ and $\epsilon_{M}$ are the Rayleigh and Mie scattering optical depths respectively. These are commonly approximated by a single polynomial term, $P(\lambda)$,

$$
\tau(\lambda)=\sum_{i}\left[\sigma_{i}(\lambda) \cdot a_{i}\right]+P(\lambda)
$$




\subsubsection{The Ring effect}

Inelastic scattering in the atmosphere leads to an observed infilling of the Fraunhofer lines. This is known as the Ring effect and is thought to be primarily caused by rotational Raman scattering (RRS) in the atmosphere (Grainger \& Ring, 1962; Vountas et al., 1998; Lampel et al., 2015). Correction of the Ring effect is essential for accurate measurements of weak absorbers (e.g. BrO).

The Ring effect is usually corrected for by treating it as an additional (or sometimes multiple) pseudo-absorbing gas species. How the Ring spectrum is produced varies - in some cases the inelastic scattering efficiency is assumed to 130 be independent of wavelength so the Ring spectrum is taken as a normalised inverse Fraunhofer spectrum. A more robust method is to model the Ring effect by applying known RRS efficiencies for atmospheric species to the Fraunhofer spectrum. In either case the Ring spectrum is included with other gas crosssections in the summation of equation 3 .

$$
S_{i}=-\ln \left[G(x) \otimes \exp \left(-\sigma_{i}(\lambda) \cdot a_{i}\right)\right]
$$

$G(x)$ is the ILS defined on the wavelength grid $x$ and $\otimes$ denotes a convolution. Note that the convolution should be applied to the gas transmission spectrum, not the optical depth, and to each gas included in the fit (as well as the Ring spectrum), however for weak absorption $(\tau(\lambda)<0.1)$, equation 4 can be approximated by pre-convolving the gas absorption cross-section with the ILS of the spectrometer:

$$
\tau(\lambda)=\sum_{i}\left[\sigma_{i}^{\prime}(\lambda) \cdot a_{i}\right]+P(\lambda)
$$

where

$$
\sigma_{i}^{\prime}(\lambda)=G(x) \otimes \sigma_{i}(\lambda)
$$

This approximation avoids the need for performing the convolution at each iteration of the fit process, speeding up the analysis. It is, however, only valid for weak absorption $(\tau(\lambda)<0.1)$. For a fit window of 310-320 nm this assumption is valid for $\mathrm{SO}_{2}$ SCDs of less than approximately $2.5 \times 10^{17}$ molecules $\mathrm{cm}^{-2}$, which are commonly found in volcanic plumes. 
The ILS is a property of the instrument and can either be measured using a spectral line source (such as a mercury lamp) or approximated by a mathematical function such as a Gaussian or "super-Gaussian" (Beirle et al., 2017). The shape of the ILS can change due to ambient temperature fluctuations so it is best to stabilise the temperature of the spectrometer, though this is not always practical due to higher power consumption.

\subsubsection{Saturation and the $I_{O}$-effect}

Related to the resolution of the spectrometer are two effects that impact DOAS retrievals. These are commonly known as saturation and the $\mathrm{I}_{0}$-effect.

In traditional DOAS retrievals both the FRS and plume spectra are measured, meaning that they are both smoothed by the spectrometer ILS. This introduces an error as a convolution does not commute with the exponential function, so the measured optical depth does not match the true optical depth when smoothed to the spectrometer resolution:

$$
\begin{aligned}
\tau^{*}(\lambda) & =-\ln \left[\frac{I^{*}(\lambda)}{I_{0}^{*}(\lambda)}\right] \\
\tau(\lambda) & =-\ln \left[\frac{I(\lambda)}{I_{0}(\lambda)}\right]=-\ln \left[\frac{G(x) \otimes I^{*}(\lambda)}{G(x) \otimes I_{0}^{*}(\lambda)}\right] \\
\tau(\lambda) & \neq G(x) \otimes \tau^{*}(\lambda)
\end{aligned}
$$

Here symbols with a ${ }^{*}$ represent the true natural spectra and those without are the measured spectra. This introduces a non-linearity in the measured optical depth with increasing $\mathrm{SO}_{2} \mathrm{SCD}$, known as the saturation effect (Wagner et al., 2002). A scaling factor is commonly used to correct for this effect (Platt \& Stutz, 2008, see section 6.7.2).

The $\mathrm{I}_{0}$-effect is slightly different to saturation and arises because the light source, in this case scattered sunlight, is highly structured. This is from where the effect draws its name. Taking the ratio of the measured FRS and plume spectrum does not entirely remove the structure of the FRS as the ratio cannot be interchanged with the convolution (Platt et al., 1997; Aliwell et al., 2002; Wagner et al., 2002; Platt \& Stutz, 2008). If we compare two optical depth spectra, one produced with a smooth light source, $I_{0, s m o o t h}^{*}(\lambda)$, and one with a structured light source, $I_{0, \text { struct }}^{*}(\lambda)$, then:

$$
\begin{aligned}
\tau_{\text {smooth }}(\lambda) & =-\ln \left[\frac{G(x) \otimes I_{\text {smooth }}^{*}(\lambda)}{G(x) \otimes I_{0, \text { smooth }}^{*}(\lambda)}\right] \\
\tau_{\text {struct }}(\lambda) & =-\ln \left[\frac{G(x) \otimes I_{\text {struct }}^{*}(\lambda)}{G(x) \otimes I_{0, \text { struct }}^{*}(\lambda)}\right] \\
\tau_{\text {smooth }}(\lambda) & \neq \tau_{\text {struct }}(\lambda)
\end{aligned}
$$


In traditional DOAS retrievals the $\mathrm{I}_{0}$-effect is routinely corrected for by producing a modified absorption cross-section (Aliwell et al., 2002, Appendix 2). This can be calculated as:

$$
\sigma_{i, c}(\lambda) \cdot a_{i, c}=-\ln \left[\frac{G(x) \otimes\left(I_{0}^{*}(\lambda) \cdot \exp \left[-\sigma(\lambda) \cdot a_{i, c}\right]\right)}{G(x) \otimes I_{0}^{*}(\lambda)}\right]
$$

In this equation a high resolution Fraunhofer spectrum, $I_{0}^{*}$, is multiplied by the transmittance of a chosen gas with SCD $a_{i, c}$ and convolved with the spectrometer ILS. This is then normalised by an ILS convolved Fraunhofer spectrum with no gas absorption to produce a synthetic plume transmittance spectrum and converted to optical depth by taking the negative natural logarithm. The corrected cross-section, $\sigma_{i, c}(\lambda)$, is then found by dividing by the assumed SCD (see equation 1 ).

The values of the correction factors used in saturation and $I_{0}$ corrections are important and will only be true for a single SCD, becoming progressively worse the further away from the true SCD the correction factor is. For example, for a typical volcanic plume SCD of $1 \times 10^{18}$ molecules $\mathrm{cm}^{-2}$ and an analysis wavelength range or $310-320 \mathrm{~nm}$ the $\mathrm{I}_{0}$-effect can introduce errors of up to approximately $5 \%$. While this is smaller than other sources of error for volcanic emission rate calculations it is still important to take this into account, especially as it introduces a systematic offset (so the error is not corrected by averaging).

\section{2. $i$ Fit}

\subsubsection{Forward model}

iFit follows a similar approach to traditional DOAS, solving equation 4 to retrieve the $\mathrm{SCD}$ of $\mathrm{SO}_{2}$ in the plume, but there are two main differences. Firstly, a literature solar spectrum is used in place of the measured FRS, eliminating the possibility of contamination. Secondly, all calculations are performed in intensity space, not optical depth, and on the higher resolution wavelength grid of the literature solar spectrum $(0.01 \mathrm{~nm})$. Rewriting equation 4 in terms of intensity gives:

$$
I(\lambda)=G(x) \otimes\left(I_{0}^{*}(\lambda) \cdot \exp \left(\sum_{i}\left[-\sigma_{i}(\lambda) \cdot a_{i}\right]+P(\lambda)\right)\right)
$$

It was found that replacing $\exp (P(\lambda))$ with the polynomial $P^{\prime}(\lambda)$ to take account of broadband features in the spectrum improved the numerical stability without impacting the fit quality. An intensity offset, $I_{\text {of fset }}(\lambda)$, is also included to account for uncorrected stray light or electronic offset in the signal, giving the final forward model of iFit:

$$
I(\lambda)=G(x) \otimes\left(I_{0}^{*}(\lambda) \cdot P^{\prime}(\lambda) \cdot \exp \left(\sum_{i}\left[-\sigma_{i}(\lambda) \cdot a_{i}\right]\right)\right)+I_{o f f s e t}(\lambda)
$$


The FRS used in iFit is taken from Chance \& Kurucz (2010). This spectrum was produced using a combination of high resolution ground- and balloonbased observations with corrections for atmospheric absorption and represents the spectrum of solar exo-atmospheric radiation. This is different to the measured FRS used in traditional DOAS which contains features from atmospheric species.

One key difference between equation 10 and equation 4 is where the ILS

220 convolution is applied. In equation 4 the ILS convolution is applied to each gas transmission spectrum separately, while for iFit it is applied once at the end of the model. This means that it is not necessary to correct for the saturation or $\mathrm{I}_{0}$ effects, making equation 10 a more physical description of the radiative transfer process. Note that there will still be some saturation effect due to the final wavelength resolution of the detector pixels, but this will be significantly less than from performing the fit in optical depth.

\subsubsection{Flat Field Response}

Most instrumental effects that impact traditional DOAS retrievals also affect iFit, including the wavelength calibration, resolution of the spectrometer and 230 the presence of the dark current, electronic offset and stray light in the measured spectrum. One effect that does not require correcting in traditional DOAS is the pixel-to-pixel variation in quantum efficiency, which is often referred to as the flat field response or pixel-to-pixel gain (Dobber et al., 2006; Kleipool et al., 2018; Munro et al., 2016). Due to slight differences in the manufacturing 235 process each individual pixel in the CCD array has a slightly different quantum efficiency, and so will record a different intensity when illuminated by a spectrally flat light source. This effect is a property of individual pixels and has no dependence on the wavelength of light illuminating the pixel, meaning it is not affected by any changes to the wavelength calibration of the spectrometer. In 240 traditional DOAS both $I(\lambda)$ and $I_{0}(\lambda)$ are measured by the same spectrometer and so the impact of the flat field response cancels out when calculating optical depth.

The flat field spectrum can be characterised with a smoothly varying light source. The measured signal is averaged across many spectra $(10,000)$ to min-

245 imise noise, correcting for systematic noise sources by subtracting by a dark spectrum taken with the lamp switched off. The broadband features are then isolated either by fitting a polynomial function or applying a boxcar smooth. The measured spectrum is then divided by the broadband features, leaving the flat field response of the spectrometer (Fig. 1). The flat field spectrum is unique for each instrument, but once measured it should remain usable for extended periods of time.

\subsubsection{Fitting procedure}

An overview of the fitting procedure is given below and displayed graphically in Figure 2. The first step in the analysis process is to interpolate the Fraunhofer 255 spectrum, all gas cross-sections and the Ring spectrum onto a model wavelength grid using a cubic spline interpolation. The model grid has a spacing of 0.01 


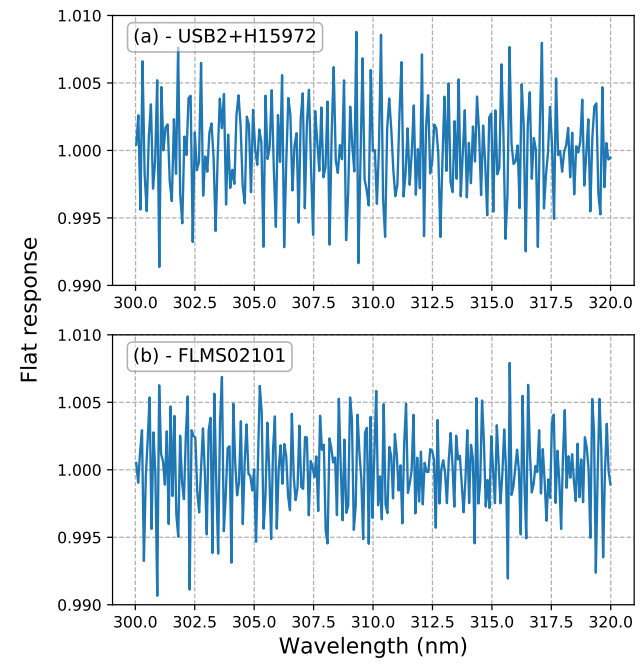

Figure 1: Example flat field responses for two Ocean Optics spectrometers: (a) a USB2000+ (USB2+H15972) and (b) a Flame-S (FLMS02101). Each spectrum is the average of 10 flat spectra, which are in turn made from 1000 measurements each with an integration time of 30 ms. The individual pixel variation across the 10 spectra was approximately 0.0001 for each spectrometer. The broadband features of the lamp were removed using a boxcar smoothed spectrum. These measurements were performed with an Ocean Optics DT-MINI-2-GS light source. 
Initial Model Setup

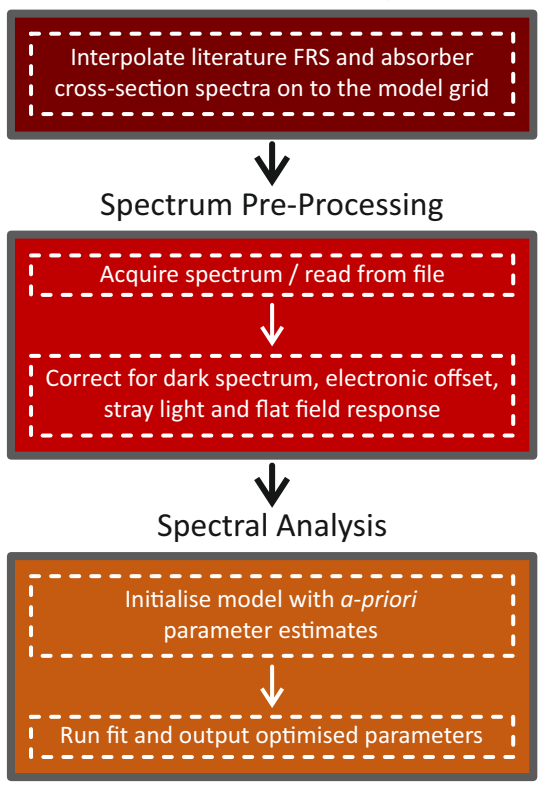

Fit Process

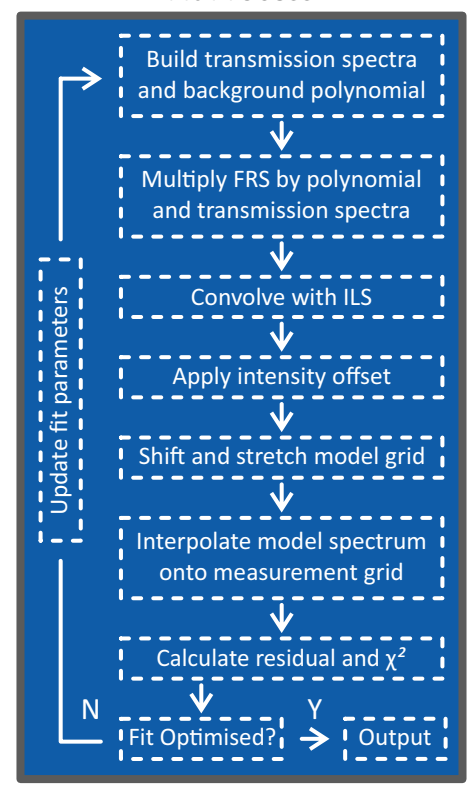

Figure 2: Flow chart for the iFit procedure.

$\mathrm{nm}$ and covers the fit window with an additional $1 \mathrm{~nm}$ padding either side. The padding is included to incorporate any wavelength shift of the spectrometer and to avoid edge effects from the ILS convolution. Note that this step only needs to be performed once for a given wavelength interval; after the cross-section spectra have been interpolated they can be stored for future use.

Before fitting the measured spectrum there are a number of pre-processing steps required. Care has been taken to minimise any transformations of the measurement in order to avoid introducing any systematic errors. Firstly the spectrum is corrected for the dark spectrum and electronic offset by subtraction of a spectrum taken with the same acquisition settings (integration time and number of averaged spectra) but with the light gathering optics blocked. A stray light correction is also applied by subtracting the average intensity between 280 and $290 \mathrm{~nm}$ (when these wavelengths are available) where there should be no 270 scattered sunlight due to complete absorption by the ozone layer. Note that the stray light signal may not be spectrally flat, however this assumption is made based on the available information from the spectrometer. Finally the measured spectrum is divided by the spectrometer flat field response. This is applied to the measurement and not the model as it is a property of the pixels and therefore independent of the wavelength calibration of the instrument. For more details on instrumental corrections see Platt \& Stutz (2008, section 7.6).

Equation 10 is then used to generate a modelled spectrum. In the first instance the modelled spectrum is determined using a-priori parameter estimates 
Table 1: Initial fit parameters for the iFit forward model. Note that a non-zero shift is used to account for the wavelength change due to refraction of light from vacuum to air (approximately $0.1 \mathrm{~nm})$.

\begin{tabular}{ccc}
\hline Parameter & Initial Value & Units \\
\hline $\mathrm{p} 0$ & 0.0 & $\mathrm{~nm}^{-3}$ \\
$\mathrm{p} 1$ & 0.0 & $\mathrm{~nm}^{-2}$ \\
$\mathrm{p} 2$ & 0.0 & $\mathrm{~nm}^{-1}$ \\
$\mathrm{p} 3$ & 1.0 & no units \\
$a_{S O_{2}}$ & $1 \times 10^{16}$ & molecules $\mathrm{cm}^{-2}$ \\
$a_{O_{3}}$ & $1 \times 10^{19}$ & molecules $\mathrm{cm}^{-2}$ \\
$a_{\text {Ring }}$ & 0.1 & arbitrary units \\
Shift & -0.1 & nm \\
Stretch & 0.0 & no units \\
Offset & 0.0 & counts \\
\hline
\end{tabular}

for the parameters, $a_{i}$, and the coefficients of the polynomial $P^{\prime}$. A slight wavelength shift and stretch of the model grid are also permitted in the fit to account for changes in the wavelength calibration with time (Platt \& Stutz, 2008, Section 8.3.3). This is applied as the addition of a polynomial to the model grid wavelength values. Finally a fixed intensity offset was included to account for any stray light or offset signal not taken into account in the spectrum pre-processing, or if suitable wavelengths for a stray light correction were unavailable. The initial guesses for each parameter used are given in Table 1. No bounds were placed on the variation of the fit parameters to avoid biasing the fit results. Finally the $\chi^{2}$ value is calculated by summing the square of the residual between the measured spectrum and model.

This $\chi^{2}$ value is then minimised using a non-linear least-squares minimisation in which the input parameters are varied until the best fit between the model and measurement is achieved. This was implemented using the LevenbergMarquardt method of the Python "leastsq" function from the scipy library (Jones et al., 2001-, version 1.3.1). The default optimisation criteria were used, as detailed in the software documentation.

The gases included in the fit were $\mathrm{SO}_{2}$ (at $295 \mathrm{~K}$, Rufus et al., 2003) and $\mathrm{O}_{3}$ (at $243 \mathrm{~K}$, Gorshelev et al., 2014). The Ring spectrum was generated using the Ring tool of the QDOAS software (Danckaert et al., 2017) with the same solar spectrum from Chance \& Kurucz (2010). Note that all reference spectra

300 should be given in vacuum wavelengths in order to match the solar spectrum and avoid wavelength shifts from refraction in air.

\section{3. $\mathrm{SO}_{2}$ Emission Rate}

Monitoring volcanic $\mathrm{SO}_{2}$ emission rates is an effective and powerful tool to understand the state of a volcanic system and the amount of degassing magma 305 below the surface. From the ground there are three main methods to achieve this with a UV spectrometer measuring scattered sunlight: by traversing under 
the plume, scanning the plume or by using an $\mathrm{SO}_{2}$ camera (Kantzas \& McGonigle, 2008; Platt et al., 2018). This section will briefly outline how these measurements are performed.

In a traverse the spectrometer is typically pointed towards zenith and transported underneath the plume. The total $\mathrm{SO}_{2}$ in a cross-section of the plume is calculated by integrating the SCDs retrieved over the distance travelled (correcting for the angle between the traverse and plume vectors). The emission rate is then found by multiplying this by the speed at which the plume is trav-

315 elling. In this case an area of clear sky is usually easy to identify as traverses are typically conducted manually by a trained operator, although automated traverses have been conducted where this is not as straight forward (Mori et al., 2017).

Scanners operate under a similar principle, but instead of transporting the spectrometer the field of view is scanned across the plume from a stationary position. The total plume cross-section can then be found by integrating across the scan, using assumptions about the location and geometry of the plume to derive the physical distance between each spectrum. Scanning spectrometers are usually deployed in networks which allow the plume location and geometry

325 to be determined and a wide range of plume directions to be covered. Examples include the Network for Observation of Volcanic and Atmospheric Change (NOVAC) (Galle et al., 2010) and the FLux Automatic MEasurements (FLAME) network (Salerno et al., 2009a).

Scanning networks are advantageous over traverse measurements as they can greatly increase the time coverage and frequency of emission rate measurements. However as these stations are automated, the FRS must be automatically selected and corrections for potential contamination applied, as discussed above. The requirement for knowledge of the plume geometry also introduces another source of uncertainty to the calculation of the emission rate (Galle et al., 2010).

$335 \quad \mathrm{SO}_{2}$ cameras utilise two wavelength channels, one sensitive to $\mathrm{SO}_{2}$ and one not, to produce images of relative absorbance (Mori \& Burton, 2006; Bluth et al., 2007). These images are then calibrated to produce SCD images, typically either with $\mathrm{SO}_{2}$ calibration cells with a known $\mathrm{SCD}$ of $\mathrm{SO}_{2}$ or by using a co-located spectrometer (Lübcke et al., 2014; Kern et al., 2015a). The emission rate can

340 then be calculated from these images by measuring the mass of gas travelling through an integration line in the image. The two main advantages of the $\mathrm{SO}_{2}$ camera are that analysis of consecutive images gives a direct measurement of the plume velocity, and that much higher time frequency degassing processes can be captured (Burton et al., 2015a). As $\mathrm{SO}_{2}$ cameras are often deployed manually it is usually straightforward to identify a region of clear sky to provide the FRS, however for permanent camera deployments (e.g. Burton et al., 2015b; Kern et al., 2015b) this is more difficult to achieve.

\section{Instrumental and Measurement details}

To test the accuracy and robustness of the iFit retrieval a series of tests were performed including spectra taken of clear sky, $\mathrm{SO}_{2}$ cells and volcanic plumes, 
including both zenith pointing and scanning measurements.

For the stationary and traverse measurements the scattered sunlight is collected using a zenith pointing collimating telescope (focal length $=100 \mathrm{~mm}$ ) coupled to the spectrometer by a fibre optic cable (diameter $=400 \mu \mathrm{m})$. A bandpass filter (Hoya U-340) was used for traverse and scanning measurements to block wavelengths above $400 \mathrm{~nm}$ and limit the impact of stray light. The spectrometer was powered and controlled using a laptop computer. The integration time of the spectrometer was manually set prior to measurements to maximise the measured intensity while avoiding saturation of the detector at any wavelength. Each measurement was averaged across 10 spectra to reduce noise. For traverses the telescope was mounted on a car and driven under the plume roughly perpendicular to the plume direction of travel. For details on the scanning measurements see Salerno et al. (2009a).

The data presented in this report were acquired using three different spectrometers, all from Ocean Optics (now Ocean Insight, https : //www . oceaninsight . com/). They are an S2000 (I2J5046), a USB2000+ (USB2+H15972) and a Flame-S (FLMS02101). Note that while iFit was developed using Ocean Optics spectrometers, the principles apply to any UV spectrometer (e.g., Kantzas et al., 2009). The flat field response of each instrument was measured using 370 an Ocean Optics DT-MINI-2-GS Deuterium Tungsten Halogen light source, averaging 10,000 individual spectra. The ILS was characterised using the 302 $\mathrm{nm}$ emission line of a mercury lamp by fitting an asymmetric super-Gaussian function as described by Beirle et al. (2017):

$$
G(x)=\left\{\begin{array}{l}
A(w, k) \times \exp \left(-\left|x / w-a_{w}\right|^{k-a_{k}}\right), x \leq 0 \\
A(w, k) \times \exp \left(-\left|x / w+a_{w}\right|^{k+a_{k}}\right), x>0
\end{array}\right.
$$

where

$$
A(w, k)=\frac{k}{2 w \Gamma\left(\frac{1}{k}\right)}
$$

and $x$ is the wavelength grid on which the ILS is defined. The parameters $w$ and $k$ control the width and shape of the super-Gaussian respectively, while $a_{w}$ and $a_{k}$ control the asymmetry. $\Gamma$ is the gamma function. For the superGaussian it is useful to use the "Full Width at e'th Maximum" (FWEM) as a measure of the resolution as opposed to the Full Width at Half Maximum $380(F W H M)$ that is more common for pure Gaussian line shapes. The $F W E M$ is defined as:

$$
F W E M=2 \times w
$$

Figure 3 shows the mercury spectra and fitted ILS for each spectrometer. The fitted super-Gaussian parameters are given in Table 2. The $302 \mathrm{~nm}$ line was chosen as it was the closest to the wavelength interval used in the fit. The 385 ILS is a function of wavelength and so different lines should be selected if fitting different regions of the spectrum. 

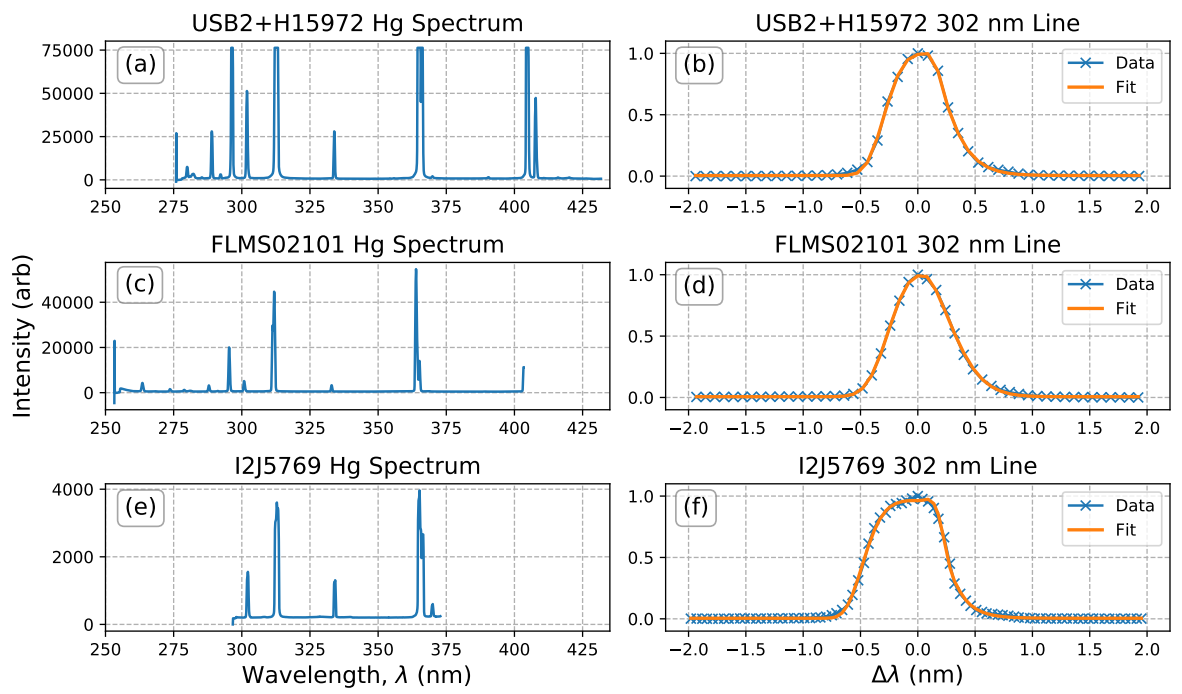

Figure 3: Mercury spectra (left column) and fitted instrument line shapes (right column) for the USB2+H15972 (top), FLMS02101 (middle) and I2J5769 (bottom) spectrometers.

Table 2: Summary of the super-Gaussian parameters for the spectrometers used in this study, fitted to the $302 \mathrm{~nm}$ emission line of a mercury lamp.

\begin{tabular}{ccccc}
\hline Serial Number & $F W E M$ & $k$ & $a_{w}$ & $a_{k}$ \\
\hline FLMS02101 & $0.713( \pm 0.003)$ & $2.19( \pm 0.03)$ & $-0.02( \pm 0.01)$ & $-0.52( \pm 0.07)$ \\
USB2+H15972 & $0.674( \pm 0.004)$ & $2.53( \pm 0.06)$ & $-0.12( \pm 0.01)$ & $-1.3( \pm 0.1)$ \\
I2J5769 & $0.815( \pm 0.004)$ & $3.34( \pm 0.07)$ & $-0.26( \pm 0.01)$ & $-2.3( \pm 0.1)$ \\
\hline
\end{tabular}

A mathematical expression for the ILS was used in place of the measured spectrum for ease as it must be generated on the model grid, not the measurement grid of the spectrometer. This also allowed the ILS parameters to be fitted alongside the model parameters listed in Table 1 to account for changes with time. Care must be taken when fitting the ILS parameters as it is highly nonlinear and makes the correct termination of the fitting routine more unstable.

\section{Results and Discussion}

This section explores the results of the tests performed by iFit, presenting spectra taken at different locations and at different times of day to demonstrate the robustness of iFit under different lighting conditions and viewing geometries.

\subsection{Clear Sky}

An important test for iFit is to fit spectra when no plume is present in order to show that the background sky spectrum can be reproduced. Figure 4 shows 

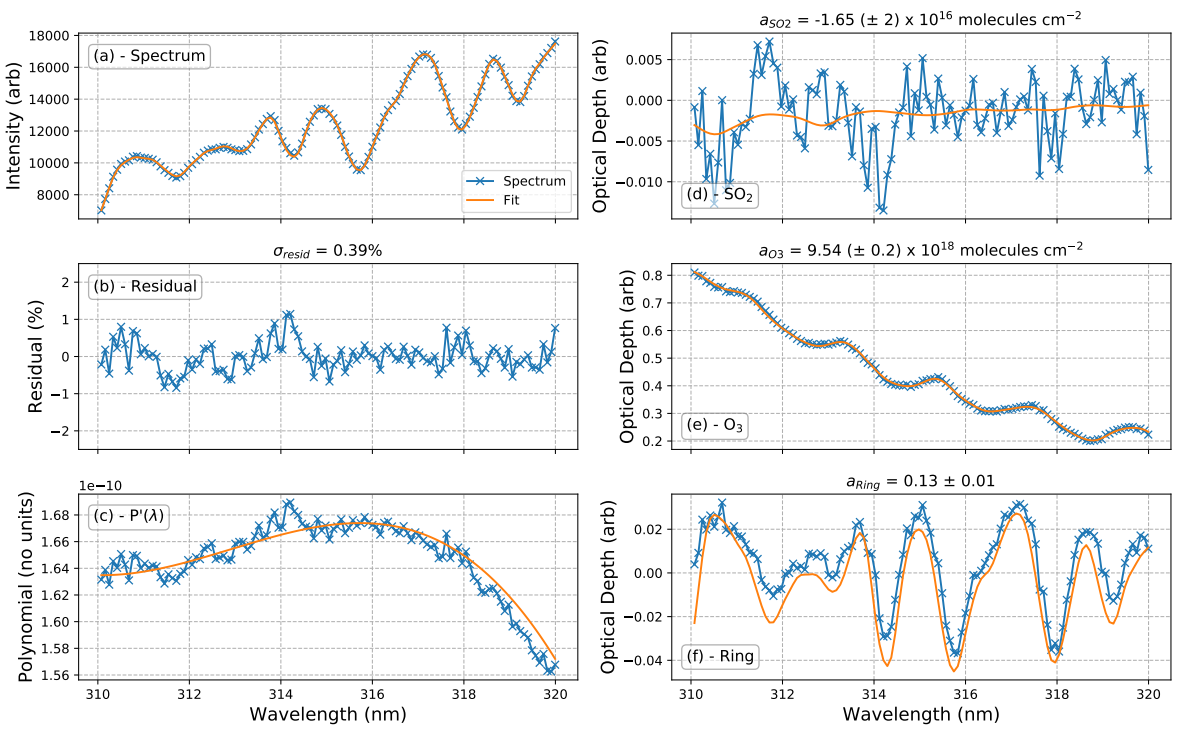

Figure 4: Example fit for a clear sky spectrum with the USB2+H15972 spectrometer at 09:30 (CST) on $14^{\text {th }}$ January 2018. (a) The measured spectrum (blue line) and model fit (orange line). (b) Percentage residual between the fit and the optimised model. Fits for the polynomial, $\mathrm{SO}_{2}, \mathrm{O}_{3}$ and Ring spectra are shown in subplots (c), (d), (e) and (f) respectively. Standard deviation of the residual and optimised parameters are given above the respective subplots.

an example of a fitted clear sky spectrum taken at Masaya volcano, Nicaragua at 9:30 am (CST) on 14 ${ }^{\text {th }}$ January 2018 using the USB2+H15972 spectrometer. In addition to the parameters listed in Table 1 the ILS parameters were fitted for this spectrum, using a purely Gaussian ILS with a FWEM of $0.65 \mathrm{~nm}$ as the initial guess. There is some systematic structure in the fit residual which remains constant during measurements. This residual could have a number of sources, including the presence of a trace absorbing gas not included in the fit, inaccuracies in the absorption cross-section spectra used or unaccounted for instrumental effects.

As iFit does not use a measured FRS under the same conditions as the measurement it may have a larger fit residual than a traditional DOAS retrieval if a recent, high quality and $\mathrm{SO}_{2}$-free FRS is used. To address whether this poses a barrier to volcanic measurements 200 clear sky spectra taken near to Masaya volcano but away from the plume between 9:37 - 9:50 (CST). The standard deviation of the retrieved SCDs was $1.3 \times 10^{16}$ molecules $\mathrm{cm}^{-2}$, giving 415 a detection limit of $3.9 \times 10^{16}$ molecules $\mathrm{cm}^{-2}$. This is easily sufficient to detect and measure typical volcanic plumes with $\mathrm{SO}_{2}$ SCDs of $>1 \times 10^{17}$ molecules $\mathrm{cm}^{-2}$. The average reported error on the $\mathrm{SO}_{2} \mathrm{SCD}$ was $2.2 \times 10^{16}$ molecules $\mathrm{cm}^{-2}$. The detection limit and uncertainty will not be universal values as they will depend on several factors, including the spectrometer resolution, integration 

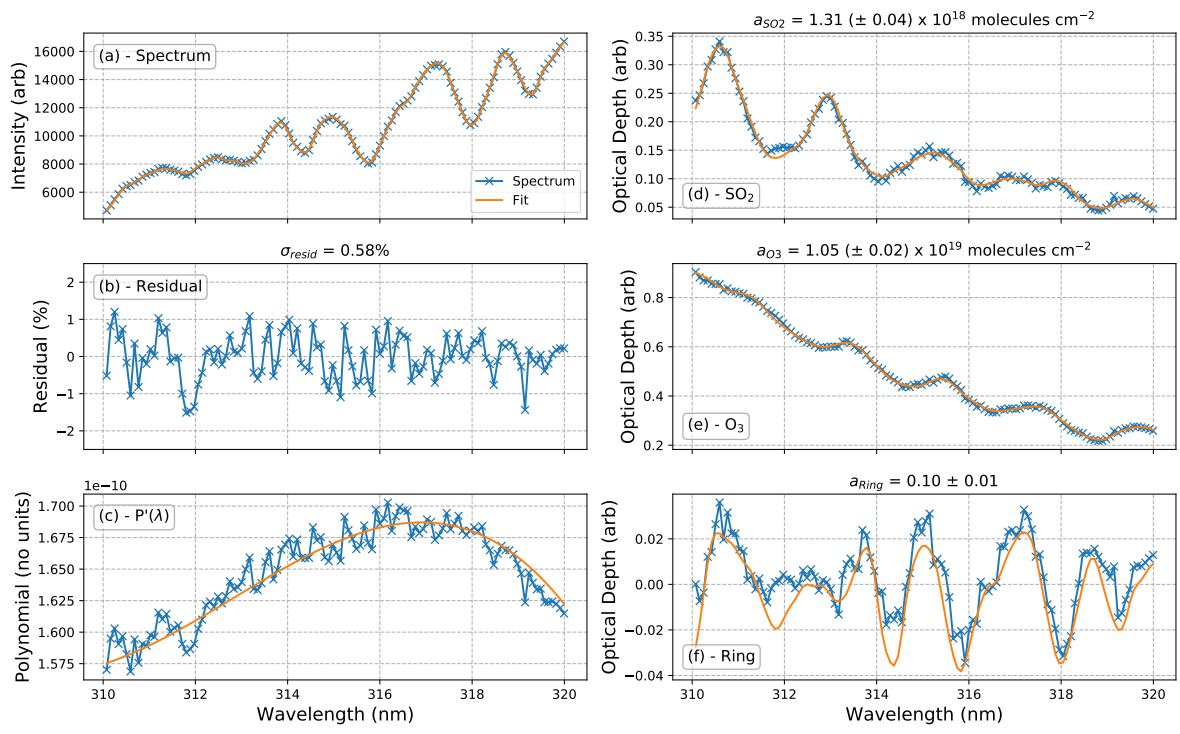

Figure 5: Example fit for a $1.28 \times 10^{18}$ molecules $\mathrm{cm}^{-2}$ cell spectrum with the USB2+H15972 spectrometer at 13:03 (CET) on $7^{\text {th }}$ September 2017. (a) The measured spectrum (blue line) and model fit (orange line). (b) Percentage residual between the fit and the optimised model. Fits for the polynomial, $\mathrm{SO}_{2}, \mathrm{O}_{3}$ and Ring spectra are shown in subplots (c), (d), (e) and (f) respectively. Standard deviation of the residual and optimised parameters are given above the respective subplots.

time used and ambient light levels.

\section{2. $\mathrm{SO}_{2}$ Cells}

\subsubsection{Stationary measurements}

Spectra were acquired using calibration gas cells filled with a known SCD of $\mathrm{SO}_{2}$. A total of 4 cells were tested, with SCDs of $1.33 \times 10^{17}, 2.64 \times 10^{17}$, $1.28 \times 10^{18}$ and $2.53 \times 10^{18}$ molecules $\mathrm{cm}^{-2}$ (as reported by the manufacturer, with stated uncertainties of $\pm 10 \%$ ). These spectra were taken from the roof of INGV Catania, Italy $\left(37.5133^{\circ} \mathrm{N}, 15.0822^{\circ} \mathrm{E}\right)$, on $7^{\text {th }}$ September 2017 under clear blue sky conditions. Approximately 50 spectra were taken of each cell using the USB2+H15972 spectrometer. Figure 5 shows an example fit of a 430 spectrum taken of the $1.28 \times 10^{18}$ molecules $\mathrm{cm}^{-2}$ calibration cell. The ILS was fitted using a pure Gaussian with a FWEM of $0.65 \mathrm{~nm}$ as the initial guess.

To investigate the effect of fitting window on retrieved $\mathrm{SO}_{2} \mathrm{SCD}$ a range of fit windows were tested by varying the lower and upper fit interval bounds (Fickel \& Delgado Granadow, 2017; Vogel et al., 2013). The lower bound was varied between 305-320 $\mathrm{nm}$ and the upper bound between 315-335 nm, both in steps of $0.2 \mathrm{~nm}$. For this analysis the $\mathrm{SO}_{2}$ spectrum from Bogumil et al. (2003) was used for this analysis as the cross-section from Rufus et al. (2003) does not extend beyond $325.2 \mathrm{~nm}$. Figure 6 shows the retrieved $\mathrm{SO}_{2} \mathrm{SCD}$ for the 

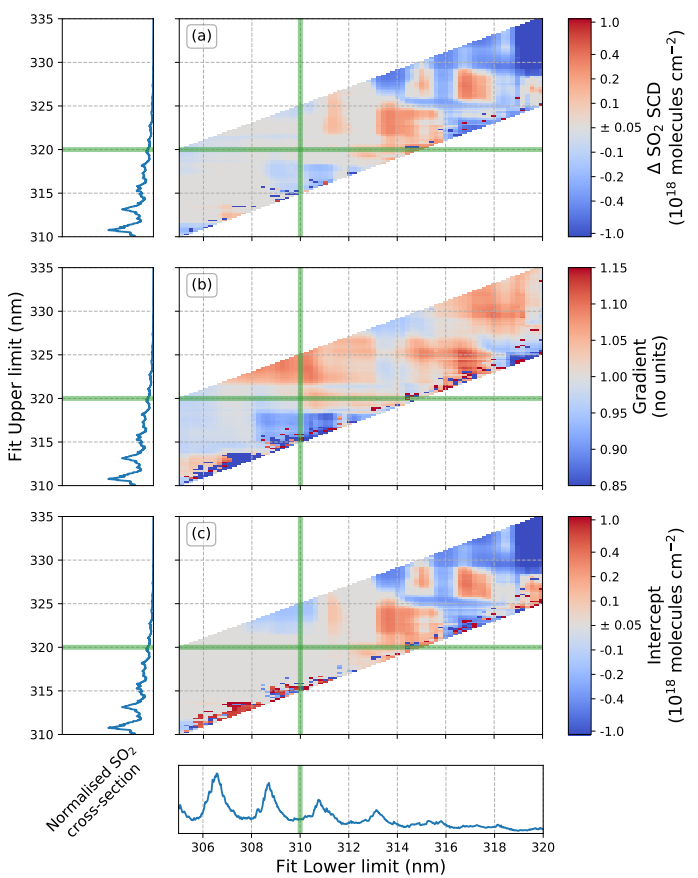

Figure 6: Wavelength interval mapping for $\mathrm{SO}_{2}$ cell spectra. (a) the residual SCD between the retrieved value and the cell value for the $1.28 \times 10^{18}$ molecules $\mathrm{cm}^{-2}$ cell. Also shown are the gradient (b) and intercept (c) of the linear fit of retrieved $\mathrm{SO}_{2} \mathrm{SCDs}$ against cell SCDs. The horizontal and vertical green lines give the upper and lower limits of the chosen fit window respectively. The normalised $\mathrm{SO}_{2}$ absorption cross-sections are shown for reference.

$1.28 \times 10^{18}$ molecules $\mathrm{cm}^{-2}$ cell as well as the gradient and intercept of a linear fit of the retrieved SCD against the actual SCD for all four cells. Each point on this figure represents a single fit of the average of all spectra taken of that cell over the given wavelength interval. The ILS was fitting between $310-320 \mathrm{~nm}$ and then fixed for the full analysis. The true ILS will change with wavelength, however fitting the ILS for each waveband often resulted the fit failing so this approximation was applied for simplicity.

This analysis shows that the fit interval has a significant impact on the retrieved SCD, especially at longer wavelengths or for narrow wavelength intervals. The offset at longer wavelengths is due to the model fitting an $\mathrm{SO}_{2}$ signal to residual structures in the fit. As the strength of the $\mathrm{SO}_{2}$ absorption decreases with increasing wavelength the magnitude the offset SCD supplied to try to fit the residual increases. The wavelength window chosen for the iFit analysis presented here $(310-320 \mathrm{~nm})$ retrieves SCDs with little offset $\left(6.7 \times 10^{15}\right.$ molecules $\mathrm{cm}^{-2}$ ) and a gradient close to unity (1.02). Note that use of shorter wavelengths risks losing signal due to near-complete absorption from atmospheric ozone. Although this depends on the time and location of measurements, typically for 


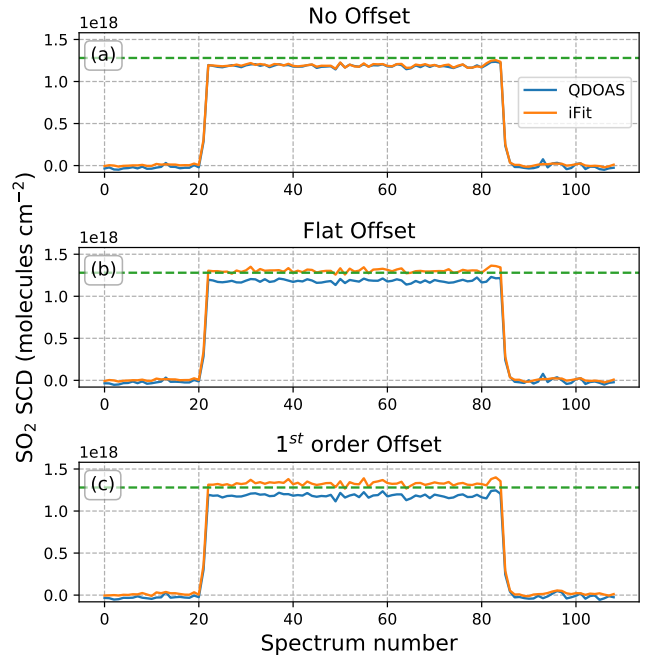

Figure 7: Retrieved $\mathrm{SO}_{2} \mathrm{SCDs}$ from a $1.28 \times 10^{18}$ molecules $\mathrm{cm}^{-2}$ calibration cell for iFit (orange) and QDOAS (blue). The green dashed line shows the cell SCD. (a) no offset correction fitted. (b) flat offset correction fitted. (c) first order offset correction fitted.

wavelengths below approximately $304 \mathrm{~nm}$ significant noise $(>10 \%)$ can be visible in the residual, and below $300 \mathrm{~nm}$ noise dominates the signal altogether. The relative impact of stray light is also more pronounced at shorter wavelengths, so care must be taken to fully correct for this.

\subsubsection{Impact of Stray Light}

One of the benefits of fitting in intensity is that it is easier to account for spectroscopic effects that introduce an offset signal. This is because these effects are simply additive in intensity, but become more complex to correct for when analysing in optical depth. To demonstrate this, spectra from the $1.28 \times 10^{18}$ molecules $\mathrm{cm}^{-2}$ calibration cell (taken without a filter to block unmeasured wavelengths) were analysed. These spectra were then analysed using iFit but without applying the pre-fit stray-light correction and with a varying degree of polynomial to fit the offset. A similar analysis was also applied using the QDOAS software for a comparison (Danckaert et al., 2017). For the QDOAS 470 analysis an $\mathrm{SO}_{2}$ spectrum, $\mathrm{O}_{3}$ spectrum, Ring spectrum and third order polynomial were included in the fit, as well as a wavelength shift and stretch. The $\mathrm{SO}_{2}$ cross-section used was corrected for the $\mathrm{I}_{0}$-effect with the $\mathrm{SCD}$ of the cell. Figure 7 shows a comparison between the two methods when no offset, a flat offset and a first order offset were included in the fit.

${ }_{475}$ Both methods underestimate the cell value when no offset correction is fitted (subplot (a)). iFit retrieves close to the true value when a flat offset is fitted (subplot (b)), and slightly overestimates when using a first order offset (subplot 
(c)). QDOAS does not show any significant change in retrieved SCD between different fitted offsets. iFit performs best in terms of both accuracy and precision

\subsection{Volcanic Plume}

\subsubsection{Traverse measurements}

Here we present results from car traverses of the plume from Masaya volcano in Nicaragua on $14^{\text {th }}$ January 2018. The telescope was mounted to a car which 520

\subsubsection{Scanning Measurements}

Here we compare iFit to the retrieval methodology used by the FLAME scanning network on Etna, Stromboli and Vulcano volcanoes in Italy Salerno et al. (2009a,b). iFit was used to analyse the same spectra presented in Section 4.2.2 of Salerno et al. (2009b). The test is described in full by the authors, so only a brief description will be provided here. Two $\mathrm{SO}_{2}$ cells were mounted to the rotating scanner head of the "ENIC" station (deployed with the I2J5769 spectrometer) to the south of Etna on days when the volcanic plume direction was away from the station location. Spectra were taken on $2^{\text {nd }}$ and $4^{\text {th }}$ August 2006 using $8.5 \times 10^{17}$ and $3.2 \times 10^{17}$ molecules $\mathrm{cm}^{-2}$ calibration cells respectively. The cells have a reported uncertainty of $\pm 5 \%$. The station performs anti-clockwise scans (east to west) covering the sky $12^{\circ}$ above each horizon $\left(12^{\circ}\right.$ to $168^{\circ}$ ) in $1.5^{\circ}$ increments. Each spectrum was taken with an integration time of $200 \mathrm{~ms}$ and averaged across 10 spectra. Each scan took approximately 5 minutes to perform and consists of 105 measurement spectra and a single dark spectrum.

Figure 8 shows a comparison with the original FLAME analysis and the reported cell column densities. Poor fits due to low intensity or saturating spectra have been removed to improve clarity. Fitting the ILS for each spectrum proved too unstable due to higher noise in the spectra than for manually acquired data. To address this the ILS was fitted for the zenith spectra of all scans shown and the average fit parameters taken. The $F W E M, k, a_{w}$ and $a_{k}$ values used were $0.765,4.8,0.25$ and 3.3 respectively. For both days the parameters agreed within a standard deviation. For both cells and both techniques there is a systematic over- or underestimation depending on the viewing direction of the scanner due to the differing ozone SCD with viewing angle, but this variation is within the reported uncertainty on the retrieved SCD. For iFit the average value agrees (within one standard deviation) with the reported cell column density, as shown in figure 8 (b) and figure 8 (d) for the $8.5 \times 10^{17}$ and $3.2 \times 10^{17}$ molecules $\mathrm{cm}^{-2}$ cells respectively.

It should also be emphasised that iFit is a preferential technique as the FLAME method uses a number of different ILS convolutions applied at different stages to fit the measured spectrum, making it a non-physical model. iFit only applies one ILS at the end of the model and so remains a (simplified) physical description of the radiative transfer process. was driven under the plume along a road approximately $3 \mathrm{~km}$ west from the 


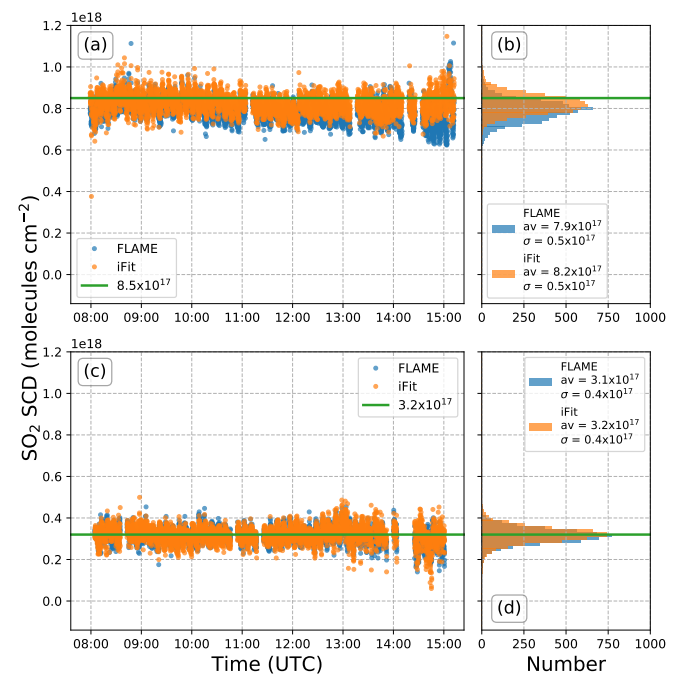

Figure 8: Retrieved $\mathrm{SO}_{2}$ SCDs for cell spectra taken using the ENIC station of the FLAME network on Etna. The iFit and FLAME results are shown in orange and blue respectively. (a) retrieved $\mathrm{SO}_{2} \mathrm{SCDs}$ and (b) histograms for the $8.5 \times 10^{17}$ molecules $\mathrm{cm}^{-2}$ cell with average and standard deviations for each. (c) retrieved $\mathrm{SO}_{2} \mathrm{SCDs}$ and (d) histograms for the $3.2 \times 10^{17}$ molecules $\mathrm{cm}^{-2}$ cell with average and standard deviations for each.

crater. The ILS parameters were fitted for each spectrum. Figure 9 shows an example fit of a plume spectrum.

The $\mathrm{SO}_{2}$ time series for two traverses are shown in Fig. 10. These spectra were also analysed using the QDOAS software (Danckaert et al., 2017), with an $\mathrm{SO}_{2}$ spectrum, $\mathrm{O}_{3}$ spectrum, Ring spectrum and third degree polynomial included in the fit, as well as a wavelength shift and stretch. The $\mathrm{SO}_{2}$ crosssection was $\mathrm{I}_{0}$ corrected using a SCD of $1.0 \times 10^{18}$ molecules $\mathrm{cm}^{-2}$. The FRS for the traditional DOAS retrieval was formed from an average of 20 spectra taken before the first traverse. Both retrievals were performed using a wavelength window of $310-320 \mathrm{~nm}$. The average ILS parameters from the iFit analysis were used for the QDOAS ILS characterisation. All spectra were corrected for dark current and stray light before analysis. Figure 10 shows that iFit agrees, within reported uncertainty, with the QDOAS result throughout the traverses.

One potential drawback of the iFit method is the reliance on the measure${ }_{535}$ ment of the flat field spectrum of the spectrometer, which requires a broadband light source. However, for spectrometers where the magnitude of the flat field spectrum is lower than the typical fit residual then analysis can be performed without applying the flat field correction. To test this the spectra from the Masaya traverse were re-analysed without applying the flat field correction. ${ }_{540}$ This reduces the quality of the fit, increasing the average residual standard deviation from $0.46 \%$ to $0.60 \%$ and resulting in a systematic change in retrieved $\mathrm{SO}_{2} \mathrm{SCD}$ of $1.6 \times 10^{16}$ molecules $\mathrm{cm}^{-2}$, approximately half the average reported 

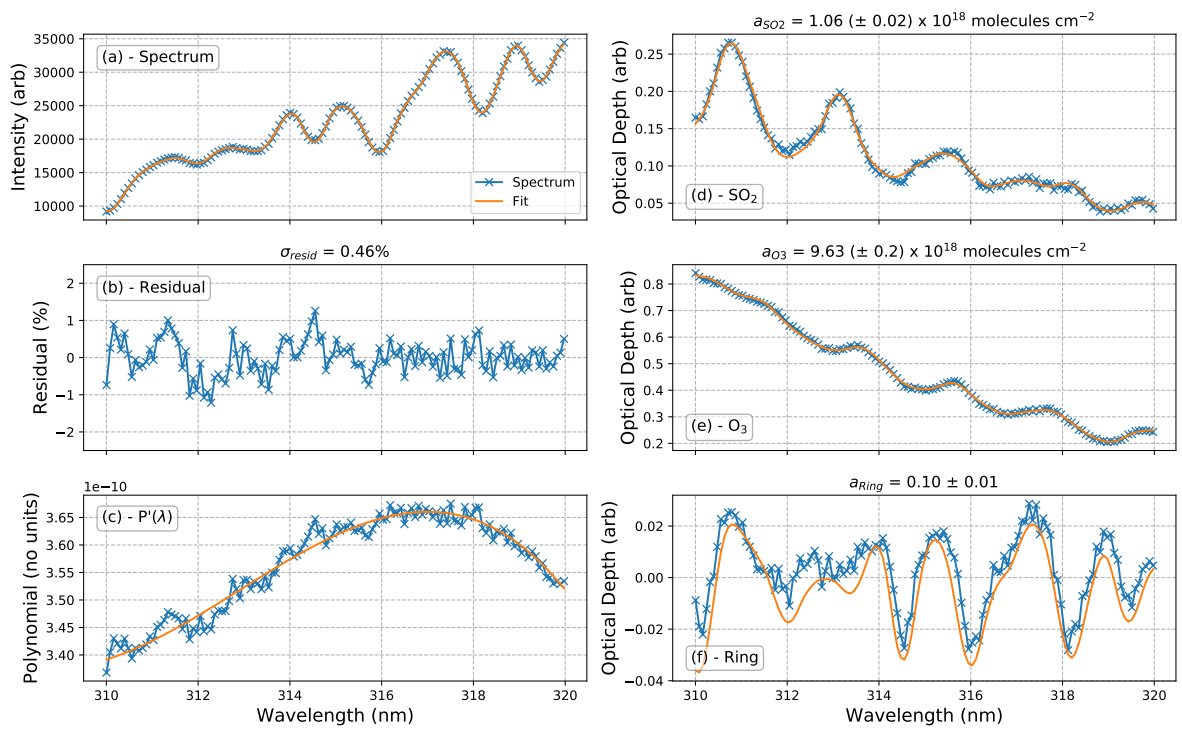

Figure 9: Example fit for an $\mathrm{SO}_{2}$ rich plume spectrum taken with the FLMS02101 spectrometer during a car traverse of the plume of Masaya volcano at 09:56 (CST) on 14 ${ }^{\text {th }}$ of January 2018. (a) The measured spectrum (blue line) and model fit (orange line). (b) Percentage residual between the fit and the optimised model. Fits for the polynomial, $\mathrm{SO}_{2}, \mathrm{O}_{3}$ and Ring spectra are shown in subplots (c), (d), (e) and (f) respectively. Standard deviation of the residual and optimised parameters are given above the respective subplots.
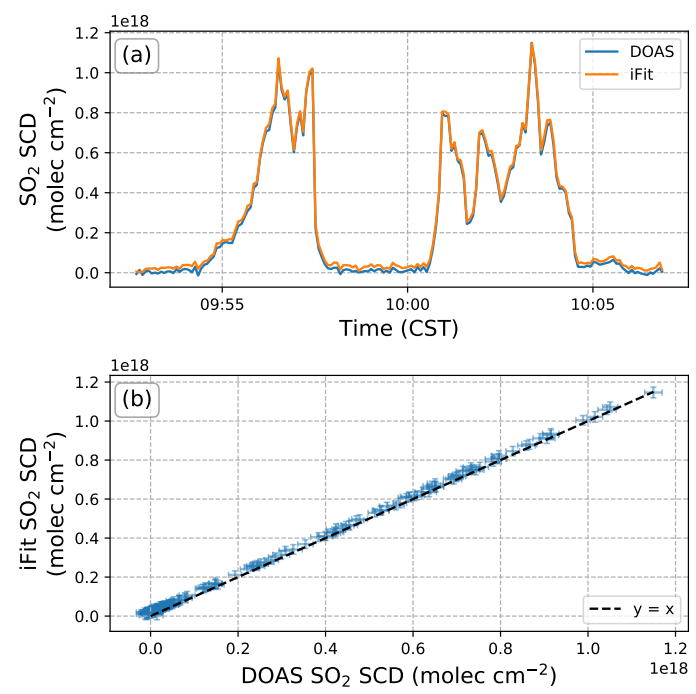

Figure 10: Two car traverses of the plume from Masaya volcano, Nicaragua, on $14^{\text {th }}$ January 2018. (a) Retrieved $\mathrm{SO}_{2}$ SCDs against time using QDOAS (blue line) and iFit (orange line). (b) Scatter plot of the iFit and traditional DOAS retrieval for each spectrum. Error bars give the reported uncertainty from the fit. The black dashed line shows $y=x$ for reference. 

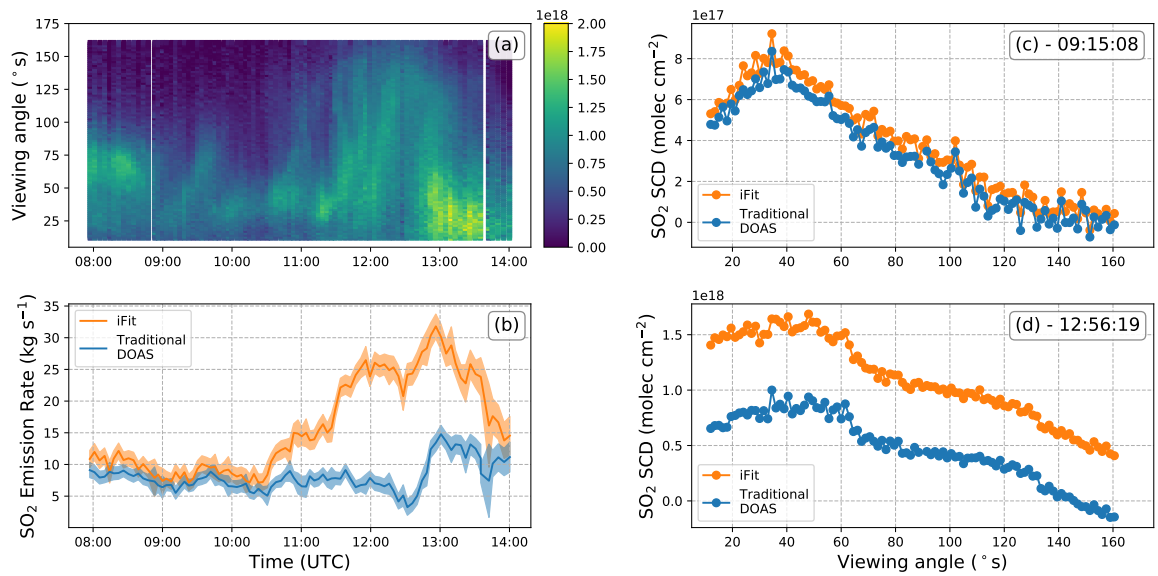

Figure 11: Retrieved $\mathrm{SO}_{2}$ SCDs for the ENIC station of the FLAME network on Etna, Italy, on $10^{\text {th }}$ August, 2014. (a) $\mathrm{SO}_{2} \mathrm{SCD}$ retrieved by iFit as a function of time and scan angle. (b) $\mathrm{SO}_{2}$ emission rate calculated from the scans for iFit (orange) and traditional DOAS analysis using the lowest $20 \%$ SCDs (blue) to calculate the contamination offset. The uncertainty from spectroscopy only is given by the shaded area. Example scans for a non-contaminated scene (c) and a contaminated scene (d) are also shown.

fit error of $2.9 \times 10^{16}$ molecules $\mathrm{cm}^{-2}$. This shows that the flat field spectrum is not necessary to retrieve $\mathrm{SO}_{2} \mathrm{SCDs}$ at an accuracy required for volcanic mea-

545 surements so long as the magnitude of the flat field correction is small, though the correction should be applied if possible.

\subsubsection{Scanning measurements}

Figure 11(a) shows the retrieved $\mathrm{SO}_{2} \mathrm{SCD}$ with respect to time and scan angle for the "ENIC" station of the FLAME network for the plume of Etna on $10^{\text {th }}$ August 2014. On this day the plume covered the field of view of the scanning station between approximately 11:20 - 13:20 (UTC), so that no plume free regions of sky were available. To highlight the issue of contamination these spectra were also analysed using a traditional DOAS retrieval using the zenith spectrum as the FRS. A contamination correction offset was applied to the traditional DOAS retrieval using the lowest $20 \%$ of SCDs for that scan as described by Galle et al. (2010). Note that scans above $162^{\circ}$ were ignored due to consistent low intensities throughout. Emission rates were then calculated for each method using the same plume heights and speeds used by the FLAME network (Salerno et al., 2009a). The plume height began at $3250 \mathrm{~m}$, decreasing smoothly 560 to $3020 \mathrm{~m}$. The plume speed began at $2.5 \mathrm{~m} \mathrm{~s}^{-1}$, increasing steadily to $4.8 \mathrm{~m}$ $\mathrm{s}^{-1}$. The scanner-plume distance was assumed to be the plume height minus the station altitude $(720 \mathrm{~m})$ across the scan. Note that the scanner-plume distance likely varies across the scan, however this assumption serves to demonstrate the issue of contamination here.

To begin with both iFit and the traditional DOAS emission rates follow 
the same trends with time until roughly 10:30 where the two trends deviate as no clear sky is visible to the scanner. This could have drastic implications for the interpretation of the $\mathrm{SO}_{2}$ emission rate time series. Examples of noncontaminated and contaminated plumes are given in sub-plots (c) and (d) respectively. The overall shape of these plumes are similar, showing that the degree of contamination is difficult to determine from the shape alone.

iFit allows the absolute SCD of each spectrum to be found, but this leaves the problem of calculating the true emission rate. If the scan is entirely covered by the plume then any emission rate calculation will be incorrect. Since an unknown amount of the plume is missing from the scan the total mass of $\mathrm{SO}_{2}$ in the scan will be wrong as well as the calculation of the plume distance from the scanner, a key parameter in determining the emission rate. Typically the plume location is calculated geometrically from the position of the centre of mass of $\mathrm{SO}_{2}$ in the scan for two scanners, so this position will be incorrect if some of the plume is missed, but the maximum SCD could be used as the plume centre instead.

Although the true $\mathrm{SO}_{2}$ emission rate could not be easily calculated without relying on significant assumptions about the plume beyond the field of view of the scanner, the ability of iFit to determine absolute SCDs will still allow the general degassing trend to be determined with greater accuracy than traditional DOAS, which is still useful for volcano monitoring.

\subsection{Computational Speed}

Performing the fit in intensity and on the high resolution model grid has the benefit of removing the need to correct for the saturation and $\mathrm{I}_{0}$ effects, but it is more computationally expensive than using the lower resolution spectrometer grid. To test the suitability of iFit for performing real time analysis a simple timing test was performed using the 171 spectra analysed for the traverse of the plume of Masaya volcano shown above. This test was performed on a laptop computer (Lenovo ThinkPad with an Intel i5 processor, $2.30 \mathrm{GHz}$ ) running an 595 implementation of the iFit procedure written in Python 3.7. Analysis of the spectra took $39.2 \mathrm{~s}(0.23$ seconds/spectrum). This is significantly slower than the time taken to analyse the spectra using QDOAS on the same laptop, which took 10.7 seconds (0.06 seconds/spectrum), however this includes iFit fitting the ILS parameters for each spectrum individually which was not applied with QDOAS. Fixing these parameters to the average values across the two traverses reduces the analysis time to $26.1 \mathrm{~s}$ ( 0.15 seconds/spectrum).

Although 0.15 seconds/spectrum is faster than typical sampling periods used for volcano monitoring (approximately 1 second), it would prove slow for reanalysing larger data sets. For this reason options to speed up the method were 605 explored. The simplest and most effective change was to update the a-priori parameter guesses for the model with the optimised values of the previous fit. This means that the initial model input is much closer to the real values, reducing the number of iterations required to produce the optimised result. This reduced the time taken to analyse the traverse data to $17.8 \mathrm{~s}$ ( 0.10 seconds/spectrum), which is comparable to QDOAS. 
The speed of the iFit analysis was further increased by changing the cubic spline interpolation at the end of each model fit iteration to a linear one. This resulted in an analysis time of $9.2 \mathrm{~s}$ (0.05 seconds/spectrum), which is as fast as QDOAS and gave identical fit results to the analysis with a cubic spline (within $0.01 \%$ ).

This shows that iFit is suitable for analysing real-time data typical for volcanic measurements, with the ability to increase the analysis speed for large data sets if required (in addition to parallel processing).

\section{Conclusions}

We have shown that it is possible to retrieve absolute volcanic $\mathrm{SO}_{2} \mathrm{SCDs}$ from scattered UV sunlight spectra using a forward model built on a high resolution FRS. The main advantage of this over the traditional DOAS method is that there is no requirement for a measured FRS, with only a simple characterisation of the spectrometer ILS and flat field response required. This reduces the complexity of the analysis and lowers the possibility of introducing systematic errors, providing a "point and shoot" tool for volcano monitoring. The lack of a requirement for a measured FRS means that iFit would be especially well suited to automated scanning spectrometer networks (such as the NOVAC (Galle et al., 2010) and FLAME (Salerno et al., 2009a) networks). iFit ${ }_{630}$ is also perfectly suited to provide accurate calibration for permanent $\mathrm{SO}_{2}$ camera stations (Burton et al., 2015b; Kern et al., 2015b) and automated traverse measurements (Mori et al., 2017).

iFit was tested on spectra of clear sky, calibration cells and volcanic plumes. The effects of the wavelength fitting window and stray light were investigated using $\mathrm{SO}_{2}$ cell data. iFit fails to supply correct absolute $\mathrm{SO}_{2} \mathrm{SCDs}$ at longer wavelengths due to the fit supplying an offset $\mathrm{SO}_{2} \mathrm{SCD}$ to account for residual features in the fit. It was found that $310-320 \mathrm{~nm}$ gives accurate results for the variety of different conditions and instruments shown here. It was also found that fits can be applied without the flat field correction for instruments where ${ }_{640}$ the flat field response is small without impacting the retrieved SCD significantly.

Changes in the ILS with time can be taken into account by including the parameters for a super-Gaussian line shape in the fit, reducing the impact of changing environmental conditions on measurements. However this slows down the analysis speed and reduces the stability of the fit, so care must be taken when applying this. As the ILS will change smoothly over time it could be updated regularly (for example once an hour) and then fixed for the remainder of the analysis.

iFit was compared to current retrieval methods - firstly to that of the FLAME network on Etna, Stromboli and Vulcano in Italy, and secondly to 650 traditional DOAS retrieval for a car traverse of the plume of Masaya volcano in Nicaragua. iFit shows good agreement with each method, suggesting that it is robust and can be routinely used in volcano monitoring. The reported uncertainty of iFit is typically higher than other methods due to residual features left over in the fit, however the practical detection limit and accuracy is suitable 


\section{Author Contribution}

Ben Esse: Conceptualisation, Methodology, Software, Investigation, Writing - Original Draft. Mike Burton: Conceptualisation, Methodology, Soft${ }_{695}$ ware, Writing - Review and Editing, Supervision. Matthew Varnam: Methodology, Investigation, Writing - Review and Editing. Ryunosuke Kazahaya: 
Methodology, Investigation, Writing - Review and Editing. Giuseppe Salerno: Validation, Writing - Review and Editing, Supervision.

\section{Appendix: Use of a fixed reference spectrum}

iFit removes the need for a measured reference spectrum, but it could be argued that a similar result could be achieved using a single, fixed FRS spectrum measured of the clear sky prior to deployment. This would remove the potential of contamination of the reference spectrum while keeping the computational efficiency of a traditional DOAS fit. However, such a method would undermine one of the primary benefits of the traditional DOAS approach: that the instrument features in the reference and measurement spectra are the same and are therefore removed through division as shown in equation 1. In particular, the ILS of the spectrometer can change with time (by as much as $0.1 \mathrm{~nm}$, Lübcke et al., 2016) which can lead to errors in the retrieved $\mathrm{SO}_{2} \mathrm{SCD}$.

Firstly, if the wrong ILS is used in the retrieval then the incorrect $\mathrm{SO}_{2} \mathrm{SCD}$ will be retrieved. This is the case for iFit as well as traditional DOAS or DOAS using a single, fixed FRS. This has led to the development of techniques to determine the ILS from the structure of Fraunhofer lines in a measured spectrum to correct for this (e.g. Beirle et al., 2017). Although not discussed here, such corrections are possible and can be applied at the analysis stage regardless of the analysis method used.

The second source of error is when the ILS changes between acquiring the FRS and measurement spectra. This will not typically effect a traditional DOAS retrieval as the FRS and measurement spectra are acquired close in time, so the ${ }_{720}$ ILS will be the same for both spectra. Similarly, this will not affect iFit (or other reference free methods) as there is no measured FRS. However, if a single, fixed FRS is used then differences in the ILS between acquiring the FRS and measurement spectra could lead to the introduction of artifacts in the measured optical depth spectrum as the instrumental effects will no longer cancel out. This disrupts the measurement itself and so would be difficult to correct for.

If a FRS is measured using the spectrometer with an ILS $G_{0}(x)$ and the plume spectrum is measured with the same spectrometer, but the ILS has changed and is now $G_{1}(x)$, then the measured optical depth, $\tau_{\text {meas }}(\lambda)$, would be calculated as:

$$
\tau_{\text {meas }}(\lambda)=-\ln \left[\frac{G_{1}(x) \otimes I^{*}(\lambda)}{G_{0}(x) \otimes I_{0}^{*}(\lambda)}\right]
$$

This means that the calculated optical depth is not equal to the product of the gas cross-section and SCD:

$$
\tau_{\text {meas }}(\lambda) \neq-\ln \left[G(x) \otimes \exp \left(-\sigma_{i}(\lambda) \cdot a_{i}\right)\right]
$$

as there is no correct ILS to use that will describe the measured optical depth spectrum, so the DOAS equation is no longer correct. 

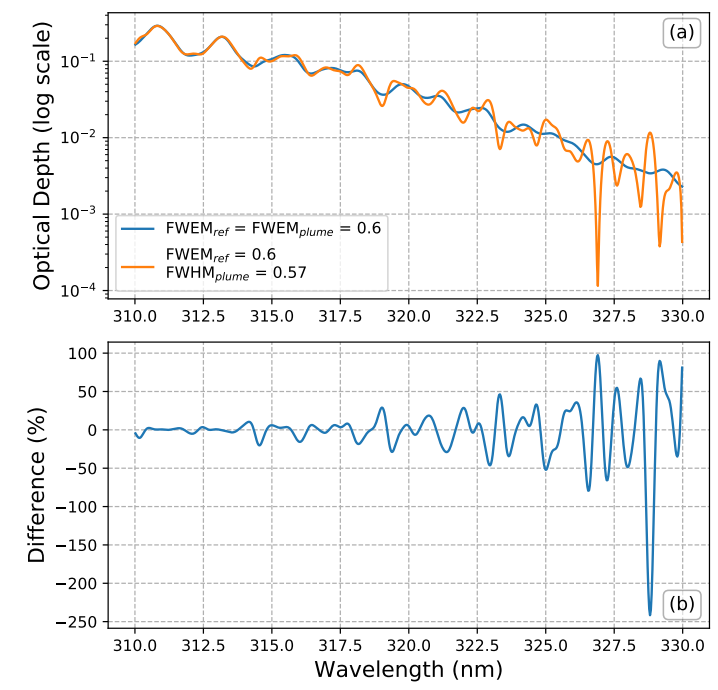

Figure A.1: Impact of changing ILS between the measured FRS and the plume spectrum. (a) modelled optical depth spectra using the same ILS for the Fraunhofer and plume spectra (blue line) and with different ILS profiles (orange line). (b) the difference between the calculated optical depths.

To demonstrate the impact of this issue a set of simulated plume spectra were generated using equation 10. The high resolution solar spectrum from Chance \& Kurucz (2010) was used as $I_{0}^{*}(\lambda)$, cross-sections for $\mathrm{SO}_{2}, \mathrm{O}_{3}, \mathrm{NO}_{2}$ and Ring were included and a purely Gaussian ILS used. The input parameters for the $\mathrm{O}_{3}, \mathrm{NO}_{2}$ and Ring spectra were set to $1.0 \times 10^{19}$ molecules $\mathrm{cm}^{-2}, 1.0 \times 10^{16}$ molecules $\mathrm{cm}^{-2}$ and 0.1 respectively. The $\mathrm{SO}_{2} \mathrm{SCD}$ was varied from 0.0 to $740 \quad 1.0 \times 10^{18}$ molecules $\mathrm{cm}^{-2}$ in steps of $1.0 \times 10^{17}$ molecules $\mathrm{cm}^{-2}$ and the Full Width at e'th Maximum (FWEM) of the Gaussian ILS was varied between 0.60, $0.57,0.54$ and $0.51 \mathrm{~nm}$ (see section 3 for more details). A simulated clear sky reference spectrum was generated with no $\mathrm{SO}_{2}$ and an Gaussian ILS with a FWEM of $0.60 \mathrm{~nm}$.

Figure A.1 shows two optical depth spectra produced from the simulated plume and reference spectra. Each has a simulated plume $\mathrm{SO}_{2} \mathrm{SCD}$ of $1.0 \times 10^{18}$ molecules $\mathrm{cm}^{-2}$, but one has been produced with the same ILS FWEM as the FRS $(0.60 \mathrm{~nm})$, while the other was produced with an ILS FWEM of $0.57 \mathrm{~nm}$.

Figure A.1 shows that using FRS and plume spectrum with different ILS FWEMs introduces high resolution structure into the measured optical depth spectrum. The main source of this structure is the shape of the Fraunhofer spectrum, not the $\mathrm{SO}_{2}$ absorption features, meaning that the structure is independent of the simulated plume $\mathrm{SO}_{2} \mathrm{SCD}$. In particular the relative amplitude of thie added structure compared to the $\mathrm{SO}_{2}$ spectrum increases with wavelength as the strength of the $\mathrm{SO}_{2}$ spectrum decreases. This means that retrievals that 


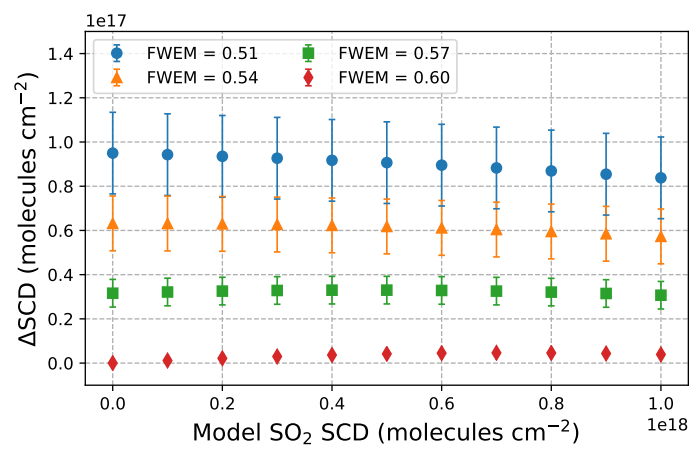

Figure A.2: Difference in retrieved $\mathrm{SO}_{2} \mathrm{SCD}$ compared to the true value as a function of simulated plume $\mathrm{SO}_{2} \mathrm{SCD}$ and ILS FWEM of the plume spectrum. The reference spectrum ILS FWEM is fixed to $0.6 \mathrm{~nm}$. The ILS used in the retrieval is the same as in the plume spectrum.

fit at longer wavelengths will be impacted more by this effect than shorter wavelengths. To test the impact on the retrieved $\mathrm{SO}_{2} \mathrm{SCD}$ the simulated spectra were analysed using QDOAS with the same settings as outlined above. The $\mathrm{SO}_{2}$ cross-section was corrected for the $\mathrm{I}_{0}$-effect using a SCD of $1.0 \times 10^{18}$ molecules $\mathrm{cm}^{-2}$ and the ILS was varied to match the ILS used to generate each plume spectrum. Figure A.2 shows the results of this analysis.

For the spectra generated with the same ILS as the FRS the retrieval returns close (within $5.0 \times 10^{15}$ molecules $\mathrm{cm}^{-2}$ ) to the correct SCD across all simulated SCDs, as would be expected. But as the difference in ILS FWEMs between the 765 FRS and measured spectra increases an offset SCD error in introduced. This error is roughly constant with simulated $\mathrm{SO}_{2} \mathrm{SCD}$ and is present even when no plume is present. This error would result in a systematic error in retrieved $\mathrm{SO}_{2}$ SCDs that would change over time as the ILS changes and could mask weaker volcanic plumes. It is important to emphasise that this error is independent of the error introduced by using the wrong ILS in the retrieval and will not impact either iFit or traditional DOAS methods.

This is not an effect that could be corrected for easily in the retrieval as it is a fundamental problem introduced by the measurement itself and results in the DOAS equation no longer correctly describing the situation. For this reason iFit 775 is a preferable method as the forward model equation remains able to describe the measurement.

\section{References}

Aliwell, S. R., Van Roozendael, M., Johnston, P. V., Richter, A., Wagner, T., Arlander, D. W., Burrows, J. P., Fish, D. J., Jones, R. L., Tømkvist,

K. K., Lambert, J. C., Pfeilsticker, K., \& Pundt, I. (2002). Analysis for $\mathrm{BrO}$ in zenith-sky spectra: An intercomparison exercise for analysis 
improvement. Journal of Geophysical Research Atmospheres, 107, 1-20. doi:10.1029/2001JD000329.

Beirle, S., Lampel, J., Lerot, C., Sihler, H., \& Wagner, T. (2017). Parameterizing the instrumental spectral response function and its changes by a super-Gaussian and its derivatives. Atmospheric Measurement Techniques, 10, 581-598. doi:10.5194/amt-10-581-2017.

Bluth, G. J. S., Shannon, J. M., Watson, I. M., Prata, A. J., \& Realmuto, V. J. (2007). Development of an ultra-violet digital camera for volcanic $\mathrm{SO}_{2}$ imaging. Journal of Volcanology and Geothermal Research, 161, 4756. doi:10.1016/j. jvolgeores. 2006.11.004.

Bobrowski, N., Hönninger, G., Galle, B., \& Platt, U. (2003). Detection of bromine monoxide in a volcanic plume. Nature, 423, 273-276. doi:10.1038/ nature01638.1.

Bobrowski, N., Kern, C., Platt, U., Hörmann, C., \& Wagner, T. (2010). Novel $\mathrm{SO}_{2}$ spectral evaluation scheme using the $360-390 \mathrm{~nm}$ wavelength range. Atmospheric Measurement Techniques, 3, 879-891. doi:10.5194/ amt-3-879-2010.

Bobrowski, N., \& Platt, U. (2007). $\mathrm{SO}_{2} / \mathrm{BrO}$ ratios studied in five volcanic plumes. Journal of Volcanology and Geothermal Research, 166, 147-160. doi:10.1016/j.jvolgeores.2007.07.003.

Bogumil, K., Orphal, J., Homann, T., Voigt, S., Spietz, P., Fleischmann, O., Vogel, A., Hartmann, M., Kromminga, H., Bovensmann, H., Frerick, J., \& Burrows, J. (2003). Measurements of molecular absorption spectra with the SCIAMACHY pre-flight model: instrument characterization and reference data for atmospheric remote-sensing in the 230-2380 nm region. Journal of Photochemistry and Photobiology A: Chemistry, 157, 167 - 184. doi:https: //doi.org/10.1016/S1010-6030(03)00062-5.

Bonaccorso, A., Calvari, S., Coltelli, M., Del Negro, C., \& Falsaperla, S. (2004). Mt. Etna: Volcano Laboratory volume 143. American Geophysical Union (AGU). doi:10.1029/GM143.

Burton, M. R., Caltabiano, T., Murè, F., Salerno, G., \& Randazzo, D. (2009). $\mathrm{SO}_{2}$ flux from Stromboli during the 2007 eruption: Results from the FLAME network and traverse measurements. Journal of Volcanology and Geothermal Research, 182, 214-220. doi:10.1016/j.jvolgeores.2008.11.025.

Burton, M. R., Oppenheimer, C., Horrocks, L. A., \& Francis, P. W. (2000). Remote sensing of $\mathrm{CO}_{2}$ and $\mathrm{H}_{2} \mathrm{O}$ emission rates from Masaya volcano, nicaragua. Geology, 28, 915-918. URL: https://doi.org/10.1130/0091-7613(2000) $28<915$ : RSOCAH> 2 . 0. CO ; 2. doi:10 . 1130/0091-7613(2000) 28<915: RSOCAH> 2.0.CO;2. 
Burton, M. R., Prata, F., \& Platt, U. (2015a). Volcanological applications of $\mathrm{SO}_{2}$ cameras. Journal of Volcanology and Geothermal Research, 300, 2-6. doi:10.1016/j.jvolgeores.2014.09.008.

Burton, M. R., Salerno, G. G., D'Auria, L., Caltabiano, T., Murè, F., \& Maugeri, R. (2015b). $\mathrm{SO}_{2}$ flux monitoring at Stromboli with the new permanent INGV $\mathrm{SO}_{2}$ camera system: A comparison with the FLAME network and seismological data. Journal of Volcanology and Geothermal Research, 300, 95-102. doi:10.1016/j.jvolgeores.2015.02.006.

Burton, M. R., Sawyer, G. M., \& Granieri, D. (2013). Deep Carbon Emissions from Volcanoes. Reviews in Mineralogy and Geochemistry, 75, 323-354. doi:10.2138/rmg. 2013.75.11.

Caltabiano, T., Romano, R., \& Budetta, G. (1994). SO $\mathrm{SO}_{2}$ flux measurements at Mount Etna (Sicily). Journal of Geophysical Research, 99, 12,809 - 12,819. doi:https://doi.org/10.1029/94JD00224.

Carn, S. A., Fioletov, V. E., Mclinden, C. A., Li, C., \& Krotkov, N. A. (2017). A decade of global volcanic $\mathrm{SO}_{2}$ emissions measured from space. Scientific Reports, 7, 1-12. doi:10.1038/srep44095.

Chance, K., \& Kurucz, R. L. (2010). An improved high-resolution solar reference spectrum for earth's atmosphere measurements in the ultraviolet, visible, and near infrared. Journal of Quantitative Spectroscopy and Radiative Transfer, 111, 1289-1295. doi:10.1016/j.jqsrt.2010.01.036.

Danckaert, T., Fayt, C., \& Van Roozendael, M. (2017). QDOAS Software user manual. Technical Report Royal Belgian Institute for Space Aeronomy. URL: http://uv-vis.aeronomie.be/software/QDOAS/.

Delgado-Granados, H., Cárdenas González, L., \& Piedad Sánchez, N. (2001). Sulfur dioxide emissions from Popocatépetl volcano (Mexico): case study of a high-emission rate, passively degassing erupting volcano. Journal of Volcanology and Geothermal Research, 108, 107-120. doi:https://doi.org/ 10.1016/S0377-0273(00)00280-8.

Dobber, M. R., Dirksen, R. J., Levelt, P. F., van den Oord, G. H. J., Voors, R. H. M., Kleipool, Q., Jaross, G., Kowalewski, M., Hilsenrath, E., Leppelmeier, G. W., Johan de Vries, Dierssen, W., \& Rozemeijer, N. C. (2006). Ozone monitoring instrument calibration. IEEE Transactions on Geoscience and Remote Sensing, 44, 1209-1238. doi:10.1109/TGRS.2006.869987.

Edmonds, M., Herd, R. A., Galle, B., \& Oppenheimer, C. M. (2003). Automated, high time-resolution measurements of $\mathrm{SO}_{2}$ flux at Soufrière Hills Volcano, Montserrat. Bulletin of Volcanology, 65, 578-586. doi:10.1007/ s00445-003-0286-x. 
Fickel, M., \& Delgado Granadow, H. (2017). On the use of different spectral windows in DOAS evaluations: Effects on the estimation of $\mathrm{SO}_{2}$ emission rate and mixing ratios during strong emission of Popocatépetl volcano. Chemical Geology, 462, 67 - 73. doi:https://doi.org/10.1016/j.chemgeo.2017.05. 001.

Fischer, T. P., Morrissey, M. M., Lucía Calvache V, M., Gómez M, D., Torres C, R., Stix, J., \& Willliams, S. N. (1994). Correlations between $\mathrm{SO}_{2}$ flux and long-period seismicity at Galeras Volcano. Nature, 368, 135 - 137. doi:https : //doi.org/10.1038/368135a0.

Galle, B., Johansson, M., Rivera, C., Zhang, Y., Kihlman, M., Kern, C., Lehmann, T., Platt, U., Arellano, S., \& Hidalgo, S. (2010). Network for Observation of Volcanic and Atmospheric Change (NOVAC) - A global network for volcanic gas monitoring: Network layout and instrument description. Journal of Geophysical Research Atmospheres, 115, 1-19. doi:10.1029/ 2009JD011823.

Galle, B., Oppenheimer, C., Geyer, A., McGonigle, A. J. S., Edmonds, M., \& 875 Horrocks, L. (2002). A miniaturised ultraviolet spectrometer for remote sensing of $\mathrm{SO}_{2}$ fluxes: A new tool for volcano surveillance. Journal of Volcanology and Geothermal Research, 119, 241-254. doi:10.1016/S0377-0273(02) 00356-6.

General, S., Bobrowski, N., Pöhler, D., Weber, K., Fischer, C., \& Platt, U. (2015). Airborne I-DOAS measurements at Mt. Etna: BrO and OClO evolution in the plume. Journal of Volcanology and Geothermal Research, 300, 175-186. doi:10.1016/j.jvolgeores. 2014.05.012.

Gorshelev, V., Serdyuchenko, A., Weber, M., Chehade, W., \& Burrows, J. P. (2014). High spectral resolution ozone absorption cross-sections \&ndash; Part 1: Measurements, data analysis and comparison with previous measurements around 293 K. Atmospheric Measurement Techniques, 7, 609-624. doi:10. 5194/amt-7-609-2014.

Grainger, J. F., \& Ring, J. (1962). Anomalous Fraunhofer line profiles. Nature, 193, 762. doi:10.1038/193762a0.

Griffith, D. W. T. (1996). Synthetic Calibration and Quantitative Analysis of Gas-Phase FT-IR Spectra. Applied Spectroscopy, 50, 59-70. doi:10.1366/ 0003702963906627.

Jones, E., Oliphant, T., Peterson, P. et al. (2001-). SciPy: Open source scientific tools for Python. URL: http://www.scipy.org/ [Online; accessed 2019-03$07]$.

Kantzas, E. P., \& McGonigle, A. J. (2008). Ground based ultraviolet remote sensing of volcanic gas plumes. Sensors, 8, 1559-1574. doi:10.3390/ s8031559. 
Kantzas, E. P., McGonigle, A. J., \& Bryant, R. G. (2009). Comparison of low cost miniature spectrometers for volcanic $\mathrm{SO}_{2}$ emission measurements. Sensors, 9, 3256-3268. doi:10.3390/s90503256.

Kantzas, E. P., McGonigle, A. J., Tamburello, G., \& Bryant, R. G. (2012). UVolc: A software platform for measuring volcanic $\mathrm{SO}_{2}$ fluxes. Computers and Geosciences, 40,194-199. doi:10.1016/j.cageo.2011.07.011.

Kern, C., Deutschmann, T., Vogel, L., Wöhrbach, M., Wagner, T., \& Platt, U. (2010). Radiative transfer corrections for accurate spectroscopic measurements of volcanic gas emissions. Bulletin of Volcanology, 72, 233-247. doi:10.1007/s00445-009-0313-7.

Kern, C., Deutschmann, T., Werner, C., Sutton, A. J., Elias, T., \& Kelly, P. J. (2012). Improving the accuracy of $\mathrm{SO}_{2}$ column densities and emission rates obtained from upward-looking UV-spectroscopic measurements of volcanic plumes by taking realistic radiative transfer into account. Journal of Geophysical Research Atmospheres, 117, 1-23. doi:10.1029/2012JD017936.

Kern, C., \& Lyons, J. J. (2018). Spatial Distribution of Halogen Oxides in the Plume of Mount Pagan Volcano, Mariana Islands. Geophysical Research Letters, 45, 9588-9596. doi:10.1029/2018GL079245.

Kern, C., Lübcke, P., Bobrowski, N., Campion, R., Mori, T., Smekens, J.F., Stebel, K., Tamburello, G., Burton, M., Platt, U., \& Prata, F. (2015a). Intercomparison of $\mathrm{SO}_{2}$ camera systems for imaging volcanic gas plumes. Journal of Volcanology and Geothermal Research, 300, 22 - 36. doi:https: //doi.org/10.1016/j.jvolgeores.2014.08.026.

Kern, C., Masias, P., Apaza, F., Reath, K. A., \& Platt, U. (2017). Remote measurement of high preeruptive water vapor emissions at Sabancaya volcano by passive differential optical absorption spectroscopy. Journal of Geophysical Research: Solid Earth, 122, 3540-3564. doi:10.1002/2017JB014020.

Kern, C., Sutton, J., Elias, T., Lee, L., Kamibayashi, K., Antolik, L., \& Werner, C. (2015b). An automated $\mathrm{SO}_{2}$ camera system for continuous, real-time monitoring of gas emissions from Kīlauea Volcano's summit Overlook Crater. Journal of Volcanology and Geothermal Research, 300, 81-94. doi:10.1016/j.jvolgeores. 2014.12.004.

Kleipool, Q., Ludewig, A., Babić, L., Bartstra, R., Braak, R., Dierssen, W., Dewitte, P.-J., Kenter, P., Landzaat, R., Leloux, J., Loots, E., Meijering, P., van der Plas, E., Rozemeijer, N., Schepers, D., Schiavini, D., Smeets, J., Vacanti, G., Vonk, F., \& Veefkind, P. (2018). Pre-launch calibration results of the TROPOMI payload on-board the Sentinel-5 Precursor satellite. Atmospheric Measurement Techniques, 11, 6439-6479. doi:10.5194/amt-11-6439-2018.

Kraus, S. G. (2006). DOASIS A framework design for DOAS. Ph.D. thesis University of Mannheim. 
Lampel, J., Frieß, U., \& Platt, U. (2015). The impact of vibrational Raman scattering of air on DOAS measurements of atmospheric trace gases. Atmospheric Measurement Techniques, 8, 3767-3787. doi:10.5194/amt-8-3767-2015.

Lerot, C., van Roozendael, M., Lambert, J.-C., Granville, J., van Gent, J., Loyola, D., \& Spurr, R. (2010). The GODFIT algorithm: a direct fitting approach to improve the accuracy of total ozone measurements from GOME. International Journal of Remote Sensing, 31, 543-550. doi:10.1080/ 01431160902893576.

Lübcke, P., Bobrowski, N., Arellano, S., Galle, B., Garzón, G., Vogel, L., \& Platt, U. (2014). $\mathrm{BrO} / \mathrm{SO}_{2}$ molar ratios from scanning DOAS measurements in the NOVAC network. Solid Earth, 5, 409-424. doi:10.5194/ se-5-409-2014.

Lübcke, P., Bobrowski, N., Illing, S., Kern, C., Alvarez Nieves, J. M., Vogel, L., Zielcke, J., Delgado Granados, H., \& Platt, U. (2013). On the absolute calibration of $\mathrm{SO}_{2}$ cameras. Atmospheric Measurement Techniques, 6, 677696. doi:10.5194/amt-6-677-2013.

Lübcke, P., Lampel, J., Arellano, S., Bobrowski, N., Dinger, F., Galle, B., Garzón, G., Hidalgo, S., Chacón Ortiz, Z., Vogel, L., Warnach, S., \& Platt, U. (2016). Retrieval of absolute $\mathrm{SO}_{2}$ column amounts from scattered-light spectra: Implications for the evaluation of data from automated DOAS networks. Atmospheric Measurement Techniques, 9, 5677-5698. doi:10.5194/ amt-9-5677-2016.

Marquard, L. C., Wagner, T., \& Platt, U. (2000). Improved air mass factor concepts for scattered radiation differential optical absorption spectroscopy of atmospheric species. Journal of Geophysical Research: Atmospheres, 105, 1315-1327. doi:10.1029/1999JD900340.

965 McGonigle, A. J. (2007). Measurement of volcanic $\mathrm{so}_{2}$ fluxes with differential optical absorption spectroscopy. Journal of Volcanology and Geothermal Research, 162, 111 - 122. doi:https://doi.org/10.1016/j.jvolgeores . 2007.02 .001 .

Moffat, A. J., \& Millan, M. M. (1971). The applications of optical correlation techniques to the remote sensing of $\mathrm{SO}_{2}$ plumes using sky light. Atmospheric Environment (1967), 5, 677-690. doi:10.1016/0004-6981(71)90125-9.

Mori, T., \& Burton, M. (2006). The $\mathrm{SO}_{2}$ camera: A simple, fast and cheap method for ground-based imaging of $\mathrm{SO}_{2}$ in volcanic plumes. Geophysical Research Letters, 33. doi:10.1029/2006g1027916.

975 Mori, T., Mori, T., Kazahaya, K., Ohwada, M., Hirabayashi, J., \& Yoshikawa, S. (2006). Effect of UV scattering on $\mathrm{SO}_{2}$ emission rate measurements. Geophysical Research Letters, 33, L17315. doi:10.1029/2006GL026285. 
Mori, T., Morita, M., Iguchi, M., \& Fukuoka Regional Headquarters (2017). Sulfur dioxide flux monitoring using a regular service ferry after the 2014 eruption of Kuchinoerabujima Volcano, Japan. J. Nat. Disaster Sci., 38, 105-118. doi:https://doi.org/10.2328/jnds.38.105.

Munro, R., Lang, R., Klaes, D., Poli, G., Retscher, C., Lindstrot, R., Huckle, R., Lacan, A., Grzegorski, M., Holdak, A., Kokhanovsky, A., Livschitz, J., \& Eisinger, M. (2016). The GOME-2 instrument on the Metop series of satellites: instrument design, calibration, and level 1 data processing - an overview. Atmospheric Measurement Techniques, 9, 1279-1301. doi:10.5194/ amt-9-1279-2016.

O'Dwyer, M., Padgett, M. J., McGonigle, A. J. S., Oppenheimer, C., \& Inguaggiato, S. (2003). Real-time measurement of volcanic $\mathrm{H}_{2} \mathrm{~S}$ and $\mathrm{SO}_{2}$ concentrations by UV spectroscopy. Geophysical Research Letters, 30, 12-15. doi:10.1029/2003GL017246.

Oppenheimer, C., Francis, P., Burton, M., Maciejewski, A., \& Boardman, L. (1998). Remote measurement of volcanic gases by Fourier transform infrared spectroscopy. Applied Physics B: Lasers \& Optics, 67. doi:10.1007/ s003400050536

Oppenheimer, C., Scaillet, B., \& Martin, R. S. (2011). Sulfur Degassing From Volcanoes: Source Conditions, Surveillance, Plume Chemistry and Earth System Impacts. Reviews in Mineralogy and Geochemistry, 73, 363-421. doi:10.2138/rmg.2011.73.13.

Pardini, F., Burton, M., Arzilli, F., La Spina, G., \& Polacci, M. (2018). SO $\mathrm{SO}_{2}$ emissions, plume heights and magmatic processes inferred from satellite data: The 2015 Calbuco eruptions. Journal of Volcanology and Geothermal Research, 361, 12-24. doi:10.1016/j.jvolgeores.2018.08.001.

Pardini, F., Burton, M., de' Michieli Vitturi, M., Corradini, S., Salerno, G., 1005 Merucci, L., \& Di Grazia, G. (2017). Retrieval and intercomparison of volcanic $\mathrm{SO}_{2}$ injection height and eruption time from satellite maps and ground-based observations. Journal of Volcanology and Geothermal Research, 331, 79-91. doi:10.1016/j.jvolgeores.2016.12.008.

Platt, U., Bobrowski, N., \& Butz, A. (2018). Ground-based remote sensing and imaging of volcanic gases and quantitative determination of multi-species emission fluxes. Geosciences, 8, 44. doi:10.3390/geosciences8020044.

Platt, U., Marquard, L., Wagner, T., \& Perner, D. (1997). Corrections for zenith scattered light DOAS. Geophysical Research Letters, 24, 1759-1762. doi:10.1029/97GL01693.

1015 Platt, U., \& Stutz, J. (2008). Differential Optical Absorption Spectroscopy. (1st ed.). Berlin Heidelberg: Springer-Verlag. 
Puķīe, J., Kühl, S., Deutschmann, T., Platt, U., \& Wagner, T. (2010). Extending differential optical absorption spectroscopy for limb measurements in the UV. Atmospheric Measurement Techniques, 3, 631-653. doi:10.5194/ amt-3-631-2010.

Queißer, M., Burton, M., Theys, N., Pardini, F., Salerno, G., Caltabiano, T., Varnam, M., Esse, B., \& Kazahaya, R. (2019). TROPOMI enables high resolution $\mathrm{SO}_{2}$ fux observations from Mt. Etna, Italy, and beyond. Scientific Reports, 9. doi:10.1038/s41598-018-37807-w.

Rufus, J., Stark, G., Smith, P. L., Pickering, J. C., \& Thorne, A. P. (2003). High-resolution photoabsorption cross section measurements of $\mathrm{SO}_{2}, 2: 220$ to $325 \mathrm{~nm}$ at $295 \mathrm{~K}$. Journal of Geophysical Research: Planets, 108. doi:10. 1029/2002JE001931.

Salerno, G. G., Burton, M., Di Grazia, G., Caltabiano, T., \& Oppenheimer, C. (2018). Coupling Between Magmatic Degassing and Volcanic Tremor in Basaltic Volcanism. Frontiers in Earth Science, 6, 1-12. doi:10.3389/feart. 2018.00157.

Salerno, G. G., Burton, M. R., Oppenheimer, C., Caltabiano, T., Randazzo, D., Bruno, N., \& Longo, V. (2009a). Three-years of $\mathrm{SO}_{2}$ flux measurements of Mt. Etna using an automated UV scanner array: Comparison with conventional traverses and uncertainties in flux retrieval. Journal of Volcanology and Geothermal Research, 183, 76-83. doi:10.1016/j.jvolgeores.2009. 02.013.

Salerno, G. G., Burton, M. R., Oppenheimer, C., Caltabiano, T., Tsanev, V. I., 1040 \& Bruno, N. (2009b). Novel retrieval of volcanic $\mathrm{SO}_{2}$ abundance from ultraviolet spectra. Journal of Volcanology and Geothermal Research, 181, 141-153. doi:10.1016/j.jvolgeores.2009.01.009.

Sparks, R. S. (2003). Forecasting volcanic eruptions. Earth and Planetary Science Letters, 210, 1-15. doi:10.1016/S0012-821X(03)00124-9.

1045 Symonds, R. B., Rose, W. I., Bluth, G. J. S., \& Gerlach, T. M. (1994). VolcanicGas Studies: Methods, Results, and Applications. In Volatiles in Magmas chapter 1. (pp. 1-66). Mineralogical Society of America volume 30. doi:10. 1515/9781501509674.

Theys, N., De Smedt, I., Yu, H., Danckaert, T., van Gent, J., Hörmann, C., ${ }_{1050}$ Wagner, T., Hedelt, P., Bauer, H., Romahn, F., Pedergnana, M., Loyola, D., \& Van Roozendael, M. (2017). Sulfur dioxide retrievals from TROPOMI onboard Sentinel-5 Precursor: algorithm theoretical basis. Atmospheric Measurement Techniques, 10, 119-153. doi:10.5194/amt-10-119-2017.

Van Roozendael, M., Spurr, R., Loyola, D., Lerot, C., Balis, D., Lambert, J.-C., Zimmer, W., van Gent, J., van Geffen, J., Koukouli, M., Granville, J., Doicu, A., Fayt, C., \& Zehner, C. (2012). Sixteen years of GOME/ERS-2 total 
ozone data: The new direct-fitting GOME Data Processor (GDP) version 5-Algorithm description. Journal of Geophysical Research: Atmospheres, 117. doi:10.1029/2011JD016471.

1060 Vogel, L., Sihler, H., Lampel, J., Wagner, T., \& Platt, U. (2013). Retrieval interval mapping: a tool to visualize the impact of the spectral retrieval range on differential optical absorption spectroscopy evaluations. Atmospheric Measurement Techniques, 6, 275-299. doi:10.5194/amt-6-275-2013.

Vountas, M., Rozanov, V. V., \& Burrows, J. P. (1998). Ring effect: impact of rotational Raman scattering on radiative transfer in Earth's atmosphere. $J$. Quant. Spectrosc. Radiat. Transfer, 60, 943-961.

Wagner, T., Chance, K., , Frieß, U., Gil, M., Goutail, F., H onninger, G., Johnson, P., Karlsen-Tørnkvist, K., Kostadinov, I., Leser, H., Petritoli, A., Richter, A., Van Roozendale, M., \& Platt, U. (2002). Correction for the Ring effect and $I_{0}$-effect for DOAS observations of scattered sunlight. Technical Report ESA. URL: http://satellite.mpic.de/pdf_dateien/RING4.pdf.

Williams-Jones, G., Stix, J., \& Hickson, C. (2008). The COSPEC Cookbook: Making $\mathrm{SO}_{2}$ Measurements at Active Volcanoes. Methods in Volcanology (1st ed.). IAVCEI. doi:10.13140/RG.2.2.13728.99845. 